\title{
Prevalence and Characterization of Staphylococcus aureus Cultured From Raw Milk Taken From Dairy Cows With Mastitis in Beijing, China
}

\section{OPEN ACCESS}

Edited by:

Maria Schirone,

Università di Teramo, Italy

Reviewed by:

Pierluigi Di Ciccio,

Università degli Studi di Parma, Italy

Jesús Santos,

Universidad de León, Spain

${ }^{*}$ Correspondence:

Fengqin $L$

lifengqin@cfsa.net.cn

Séamus Fanning

sfanning@ucd.ie

Zulqarnain Baloch

znbalooch@yahoo.com

tThese authors have contributed equally to this work and co-first authors

Specialty section:

This article was submitted to

Food Microbiology,

a section of the journal

Frontiers in Microbiology

Received: 07 March 2018

Accepted: 14 May 2018

Published: 22 June 2018

Citation:

Wang $W$, Lin $X$, Jiang $T$, Peng $Z, X U$ J,

Yi L, Li F, Fanning $S$ and Baloch Z

(2018) Prevalence and

Characterization of Staphylococcus aureus Cultured From Raw Milk Taken

From Dairy Cows With Mastitis in Beijing, China.

Front. Microbiol. 9:1123. doi: 10.3389/fmicb.2018.01123

\begin{abstract}
Wei Wang ${ }^{1 \dagger}$, Xiaohui Lin ${ }^{2 \dagger}$, Tao Jiang ${ }^{1}$, Zixin Peng ${ }^{1}$, Jin $\mathrm{Xu}^{1}{ }^{1}$, Lingxian $\mathrm{Yi}^{3}$, Fengqin $\mathrm{Li}^{1 *}$, Séamus Fanning ${ }^{1,4,5 *}$ and Zulqarnain Baloch ${ }^{3 *}$

${ }^{1}$ Key Laboratory of Food Safety Risk Assessment, Ministry of Health, China National Center for Food Safety Risk Assessment, Beijing, China, ${ }^{2}$ Physics and Chemical Department, Tianjin Center for Disease Control and Prevention, Tianjin, China, ${ }^{3}$ College of Veterinary Medicine, South China Agricultural University, Guangzhou, China, ${ }^{4}$ UCD-Centre for Food Safety, School of Public Health, Physiotherapy and Sports Science, University College Dublin, Dublin, Ireland, ${ }^{5}$ School of Biological Sciences, Institute for Global Food Security, Queen's University Belfast, Belfast, United Kingdom
\end{abstract}

The colonization of dairy herds and subsequent contamination of raw milk by Staphylococcus aureus (S. aureus), especially those expressing a multi-drug resistance (MDR), biofilm and toxins producing ability, remains an important issue for both the dairy producer and public health. In this study, we investigated the prevalence, antimicrobial resistance, virulence, and genetic diversity of $S$. aureus in raw milk taken from 2 dairy farms in Beijing, China. Ninety (46.2\%, 90/195) samples were positive for S. aureus. Resistant to penicillin (PEN) (31.3\%), ciprofloxacin (18.8\%) and enrofloxacin (15.6\%) were the most often observed. Isolates cultured from farm B showed significantly higher resistance to penicillin (73.9\%), ciprofloxacin (34.8\%), enrofloxacin (34.8\%), tilmicosin (17.4\%), and erythromycin (17.4\%) than those from farm A $(p<0.05)$. Totally, $94.8 \%$ S. aureus harbored at least one virulence gene and the pvl (93.8\%), sec (65.6\%), and sea $(60.4 \%)$ genes were the most frequently detected. The $p v /$ and sec genes were more often detected in isolates from farm A (97.3\% and $84.9 \%$ respectively) than those from farm B ( $p<0.05)$. Of all 77 staphylococcus enterotoxin (SE)-positive isolates, more than $90 \%$ could produce enterotoxins and $70.1 \%$ could produce two types. Biofilm related genes (icaA/D, clf/B, can, and fnbA) were detected in all96 isolates. All 96 isolates could produce biofilm with $8.3,70.8$, and $18.8 \%$ of the isolates demonstrating weak, moderate and strong biofilm formation, respectively. A total of 5 STs, 7 spa types (1 novel spa type t17182), 3agr types (no agrll), and 14 Smal-pulso-types were found in this study. PFGE cluster II-CC1-ST1-t127-agr III was the most prevalent clone (56.3\%). Isolates of agr III (PFGE Cluster I/II-CC1-ST1-t127/2279) had higher detection of virulence genes than those of agr I and agr IV. TheMSSA-ST398-t1456-agr I clone expressed the greatest MDRbut with no virulence genes and weakly biofilm formation. Our finding indicated a relatively high prevalence of $S$. aureus with less antimicrobial resistance but often positive for enterotoxigenicity and biofilm formation. This study could help identify predominant clones and provide surveillance measures to eliminate and decrease the contamination of $S$. aureus in raw milk of dairy cows with mastitis.

Keywords: Staphylococcus aureus, raw milk, mastitis, antimicrobial susceptible test, virulence factors, enterotoxin production, biofilm, molecular typing 


\section{INTRODUCTION}

Staphylococcus aureus (S. aureus) is one of the leading sources of intra-mammary infections in dairy cows (Dufour et al., 2012; Zecconi and Scali, 2013). It is reported that 10-40\% of the mastitis cases are caused by $S$. aureus in China and other countries (Kateete et al., 2013; Basanisi et al., 2017; Liu et al., 2017). Mastitis is a global challenge that it can result in financial losses for the dairy industry and the economy due to the substandard quality of milk, treatment costs, and causing subsequent new infection of other cows (Schroeder, 2012). Contaminated raw milk at farm level, may lead to subsequent problems further along the food chain giving rise to S. Aureus associated food contamination (Jakobsen et al., 2011; Rola et al., 2016).

S. aureus associated food poisoning in humans and similarly mastitis in animal is caused by those isolates possessing virulence factors (Hennekinne et al., 2012). This bacterium produces wide range of factors, for example toxic shock syndrome toxin-1 (TSST-1), staphylococcus enterotoxin (SE), and PantonValentine leukocidin (PVL). SEs is regarded as the major cause of S. aureus associated food poisoning (Bergdoll et al., 1981; Hennekinne et al., 2012). It is reported that more than $90 \%$ of S. aureus-associated food poisoning outbreaks were attributed to the classical SEs (denoted as SEA to SEE) encoded by sea to see genes (Tarekgne et al., 2016). The TSST-1 toxin could result in toxic shock syndrome by reducing the host immune response, while PVL could destruct host leukocyte and cause tissue necrosis (Schlievert et al., 1981).

Antimicrobial therapy is an important strategy for mastitis control as well as human infections (Gomes and Henriques, 2016). However, S. aureus often exhibit resistance to multiple classes of antimicrobial agents as a response to the selective pressure of antimicrobials, which will narrow the treatment options for clinicians and veterinarians (Gomes and Henriques, 2016). It is reported that many $S$. aureus-associated food poisoning outbreaks were due to multi-drug resistant (MDR) S. aureus including methicillin-resistant S. aureus (MRSA) (Johler et al., 2015; Jans et al., 2017). Furthermore, formation of biofilms, highly organized multicellular complexes, is often associated with both epithelial adhesion and evasion of host immune defenses (Melchior et al., 2009). Biofilm associated protein (Bap) plays an important role in primary attachment and recruitment of $S$. aureus (Khoramian et al., 2015; Felipe et al., 2017). The icaA and icaD genes that form part of the ica $A B C D$ gene cluster (intracellular adhesion locus) are essential for biofilm formation (Khoramian et al., 2015; Felipe et al., 2017). Additionally, the collagen binding proteins (Cna), clumping factors (ClfA and ClfB) and fibronectin binding proteins (FnbA and FnbB) also have associations with biofilm production according to previous studies (Khoramian et al., 2015; Pereyra et al., 2016).

Molecular epidemiology-based methods are essential tools for the study of clonal relatedness, genetic diversity, and also tracking the dissemination of $S$. aureus infections. It was reported that certain $S$. aureus lineages were specifically associated with milk, such as CC97 (Clonal complex), and particular clonal lineages may be prevalent geographically, and have specific antimicrobial resistance and virulence patterns (Hata et al., 2010). This study aimed to estimate the prevalence of $S$. aureus among raw milk from dairy cows with clinical mastitis from two dairy farms during August to December in 2016 in Beijing, China, and to describe the characteristics of the isolates, in order to provide groundwork for further studies on the control and prevention of contamination of $S$. aureus in raw milk of dairy cows with mastitis.

\section{MATERIALS AND METHODS}

\section{Sampling and Isolation of $S$. aureus}

Recruitment of cows into this study was done in consultation with veterinarians and sampling process was carried on with the agreement of the dairy farms' owners. Raw milk samples were collected from cows presenting with clinical mastitis consistent with poor milk yield, color change and udders inflammation. Milk collection process was performed after cleaning the teats, initial streams of milk discarded and teat tips scrubbed with cotton balls moistened with $75 \%$ alcohol. Teat-cleaning before milking and treatment with antibiotics at dry-off were not performed. In total, one milk sample from each cow was collected and 195 individual milk samples of 195 cows were obtained from 2 dairy farms during August to December in 2016 in Beijing, China. These two dairy farms belong to one of the largest dairy production companies in China, which mainly supply consumers in Beijing and other regions in China, and also export internationally. Both farms were managed with an intensive breeding system, with the herd size of about 500 locating cows.

The $S$. aureus contamination was detected in raw milk samples according to National Food Safety Standards of China document GB 4789.10-2016. Briefly, a 25-ml milk sample was taken and mixed thoroughly, and then transferred into $225 \mathrm{~mL} \mathrm{10 \%} \mathrm{(w/v \% )}$ saline solution (Land Bridge, Beijing, China) and homogenize it and solutions were incubated at $37^{\circ} \mathrm{C}$ for $24 \mathrm{~h}$. A loopful of the incubated culture were streaked onto Baird-Parker Agar supplemented with 5\% egg yolk and tellurite, and Blood Agar with sterile defibrinated sheep blood (Land Bridge, Beijing, China), respectively, then incubated at $37^{\circ} \mathrm{C}$ for $24-48 \mathrm{~h}$. Putative $S$. aureus isolates were tested for coagulase activity, and were further confirmed using API STAPH test strips (bio-Mérieux, Marcyl'Etoile, France). Finally, all isolates were subjected the detection of 16SrRNA and nuc genes by PCR (Table 1; Murakami et al., 1991). All confirmed S. aureus isolates were stored in BHI with $40 \%$ [v/v\%] glycerol (Land Bridge, Beijing, China) at $-80^{\circ} \mathrm{C}$. No more than 2 isolates of each sample were chose for subsequent studies.

\section{Antimicrobial Susceptibility Testing (AST)}

In this study, broth dilution method was applied to estimate the antimicrobial susceptibility of all tested isolates using the Biofosun ${ }^{\circledR}$ Gram-positive panel (Fosun Diagnostics, Shanghai, China) and interpreted by the Clinical and Laboratory Standards Institute (CLSI) (CLSI, 2015). The antimicrobial agents 
TABLE 1 | Primers used in this study.

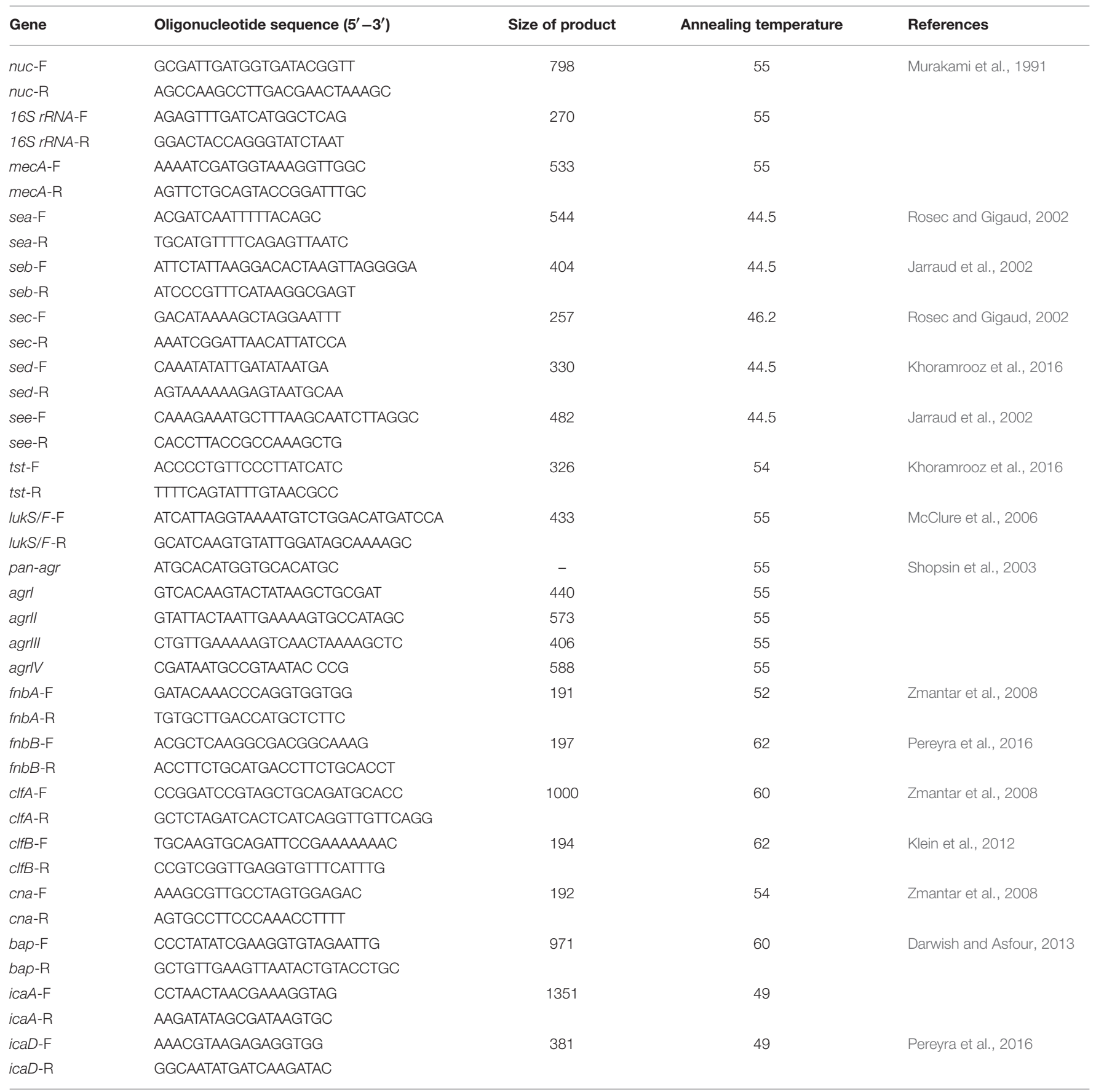

included Ceftiofur (EFT) $(0.25-64 \mu \mathrm{g} / \mathrm{mL})$, Chloramphenicol (CHL) (0.5-128 $\mu \mathrm{g} / \mathrm{mL})$, Ciprofloxacin (CIP) (0.125$16 \mu \mathrm{g} / \mathrm{mL})$, Daptomycin (DAP) $(0.06-16 \mu \mathrm{g} / \mathrm{mL})$, Enrofloxacin (ENO) (0.125-32 $\mathrm{g} / \mathrm{mL})$, Erythromycin (ERY) (0.125$16 \mu \mathrm{g} / \mathrm{mL}$ ), Fosfomycin (FOS) $(0.5-256 \mu \mathrm{g} / \mathrm{mL})$, Gentamycin (GEN) $\quad(0.5-64 \mu \mathrm{g} / \mathrm{mL})$, Penicillin (PEN) $(0.06-32 \mu \mathrm{g} / \mathrm{mL})$, Tetracycline (TET) $(0.25-64 \mu \mathrm{g} / \mathrm{mL})$, Tilmicosin (TIL) $(0.5-$ $64 \mu \mathrm{g} / \mathrm{mL}$ ), and Vancomycin (VAN) $(0.06-128 \mu \mathrm{g} / \mathrm{mL})$. $S$. aureus $\mathrm{ATCC}^{\mathrm{TM}} 29213$ was used as the reference strain for the AST.

\section{Detection of MRSA, Virulence and Biofilm Related Genes}

Frozen isolates were cultured overnight at $37^{\circ} \mathrm{C}$ in BHI (Land Bridge, Beijing, China). The genomic DNA was then extracted with TIANamp Bacterial DNA extraction kit (TianGenDNA Kit DP302, Beijing, China), and the quality of DNA was evaluated by a NanoDrop-2000 spectrophotometer (Thermo Fisher Scientific, $\mathrm{NH}$, USA). Sterile deionized water was used to dilute the extracted DNA to $50 \mathrm{mg} / \mathrm{L}$, which was suitable for real-time PCR assays. The genes encoding the methicillin resistance gene 
(mecA), SEs (sea to see), toxic-shock syndrome toxin (tst), Panton-Valentine leukocidin ( $l u k F)$, biofilm related genes (bap, $i c a A$, and $i c a D)$, and adhesion related genes ( $f n b A, f n b B, c l f A$, $c l f B$, and $c a n$ ) were detected by PCR. The primers were supplied by Thermo Fisher Scientific (Waltham, MA, USA; Table 1). Positive and negative controls were included in all PCRs.

\section{Detection of SEs Production}

SEs (SEA to SEE)production was detected by immuno-colloidal gold chromatographic test strips (Longrunbio, Beijing, China). In brief, the supernatant of $24 \mathrm{~h}$ cultures of $S$. aureus $\left(1 \times 10^{9}\right.$ $\mathrm{CFU} / \mathrm{mL}$ ) positive with SEs genes grown at $37^{\circ} \mathrm{C}$ in a shaketube (Xuzhou Yanjia Glass Products, Xuzhou, China) containing $5 \mathrm{~mL}$ BHI (Land Bridge, Beijing, China) was separated from cells by centrifugation at $8,000 \times \mathrm{g}$ for $20 \mathrm{~min}$. The supernatant was heated at $100^{\circ} \mathrm{C}$ for $10 \mathrm{~min}$. Then $200 \mu \mathrm{L}$ of the heated supernatant were tested for the presence of the SEs by the strip test assay. The samples $100 \mathrm{ng} / \mathrm{mL}$ of SEA to SEE were used as a positive control and phosphate buffer was used as negative control.

\section{Biofilm Formation}

Biofilm production was assessed by a 96-well microtiter plate assay using minimal medium $\mathrm{M} 9\left(6 \mathrm{~g} / \mathrm{l} \mathrm{Na}_{2} \mathrm{HPO}_{4}, 3 \mathrm{~g} / \mathrm{l} \mathrm{K \textrm {K } _ { 2 }} \mathrm{PO}_{4}\right.$, $0.5 \mathrm{~g} / \mathrm{l} \mathrm{NaCl}, 1 \mathrm{~g} / \mathrm{l} \mathrm{NH} \mathrm{NH}_{4} \mathrm{Cl} 2 \mathrm{mM} \mathrm{MgSO} 4,0.1 \%$ glucose, and $0.1 \mathrm{mM} \mathrm{CaCl} 2$; Müsken et al., 2010). After overnight growth in tryptone soy broth medium (TSB; Oxoid Ltd., Basingstoke, $\mathrm{UK}), 200 \mu \mathrm{L}$ of cell suspension diluted to $1: 100$ was transferred into each microtiter plate well, and the later was incubated at $37^{\circ} \mathrm{C}$ for $72 \mathrm{~h}$. After three brief washes with $200 \mu \mathrm{L}$ phosphatebuffered saline (PBS) solution and a 20-min fixation step with $200 \mu \mathrm{L}$ methanol, all plates were stained with $200 \mu \mathrm{L} 0.4 \%$ (wt/vol) crystal violet $(\mathrm{CV})$ for $15 \mathrm{~min}$ and washed with 200 $\mu \mathrm{L}$ PBS for another $15 \mathrm{~min}$. The formed biofilm was then dissolved with $200 \mu \mathrm{L} \mathrm{33 \%}$ (wt/vol) acetic acid for $30 \mathrm{~min}$. The biofilm formation was measured at $570 \mathrm{~nm}$ optical density (OD) in a micro-titer plate reader (Tecan, Mannedorf, Switzerland). Salmonella Typhimurium ATCC14028, a strong biofilm-forming strain, was selected as the positive control and sterile TSB was used as negative control for the biofilm production assays (Yan et al., 2015). These biofilm assays were performed in triplicate that included biological duplicates. An $\mathrm{OD}_{570 \mathrm{~nm}}$ value of 0.6 was applied as the cutoff point to distinguish between biofilm producer from non-biofilm producer [cut-off $(\mathrm{ODc})=$ average OD plus 3 standard deviation (SD) of negative control]. The biofilm formation was classified as strong $+++\left(\mathrm{OD}_{570 \mathrm{~nm}}>1.8\right)$, moderate $++\left(1.8>\mathrm{OD}_{570 \mathrm{~nm}}>1.2\right)$, weak $+\left(1.2>\mathrm{OD}_{570 \mathrm{~nm}}>\right.$ $0.6)$, and negative $-\left(\mathrm{OD}_{570 \mathrm{~nm}}<0.6\right)$.

\section{Multilocus Sequence Typing (MLST)}

All S. aureus isolates were examined by MLST, based on the sequencing of 7 housekeeping genes described previously (Enright et al., 2000). Alleles and the sequence type (ST) were assigned according to the $S$. aureus MLST database (http://www. mlst.net/). The STs were then clustered in to clonal complexes (CC) by eBURST v.3 software (http://eburst.mlst.net; Feil et al., 2004).

\section{spa Typing}

The spa typing for all $S$. aureus isolates was performed as described previously (Harmsen et al., 2003). The spa repeats and types were assigned by the Bio Numerics software v.7.5 (Applied Math, Belgium). If a spa repeat did not match any spa types, the sequence of this spa was then upload to the Ridom Spa Server database (http://spa.ridom.de) to assign a new type.

\section{agr Genotyping}

The agr type of all S. aureus isolates was determined using the agrgroup specific primers (agr allele types I-V) and agr multiplex PCR as described previously (Table $\mathbf{1}$ ).

\section{Pulsed-Field Gel Electrophoresis (PFGE)}

The genetic relationships of all S. aureus isolates were established by PFGE (Murchan et al., 2003; Ribot et al., 2006). In brief, the tested isolates were cultured and plugs were prepared. Chromosomal DNA was digested with the endonuclease SmaI (20 units $/ \mu \mathrm{L}$, New England Biolabs) at $30^{\circ} \mathrm{C}$ for $3 \mathrm{~h}$. The electrophoresis was performed in $1 \%$ agarose SeaKem Gold gel in the CHEF DR III apparatus (Bio-Rad, Hercules, California z) at $14^{\circ} \mathrm{C}$ for $19 \mathrm{~h}$. Macro restriction patterns were interpreted by Bio Numerics software v.7.5 (Applied Math, Belgium) by the un weighted pair group method with arithmetic averages (UPGMA). Salmonella Braenderup H9812 was used as a standard size marker.

\section{Simpson's Index of Diversity Calculation}

The Simpson's index of diversity (diversity index, DI) was used to evaluate the genetic diversity and discriminatory ability of different typing methods. The formula is as follows:

$$
D I=1-\frac{1}{[N(N-1)]} \sum_{j-1}^{s} n_{j}\left(n_{j}-1\right)
$$

$n_{j}$ is the number of isolates belonging to the $j$ th type, and $N$ is the total number of tested isolates.

\section{Statistical Analysis}

The Chi-square test was calculated using SPSS 20.0 (SPSS, Chicago, USA), in order to analyze the differences in the prevalent rates, the proportion of isolates resistant to antimicrobial agents, and the distribution of virulence genes, biofilm related genes, enterotoxin production, and biofilm production ability between two farms. Values of $p<0.05$ were considered statistically significant.

\section{RESULTS}

\section{Isolation and Identification of S. aureus}

Of the 195 raw milk samples, 90 (46.2\%, 90/195) were confirmed with $S$. aureus, and in all 96 isolates were obtained in this study (Table 2). Twelve isolates cultured from six samples (2 isolates were cultured per samples), respectively, were included in this study, as both strains of each sample were subsequently found to have different genetic patterns and/or phenotypes (Table 3 and Figure 1). Of the 90 S. aureus-positive samples, 71 of 147 (48.2\%) 
TABLE 2 | Prevalence of S. aureus in raw milk in Beijing.

\begin{tabular}{lcccc}
\hline Farm & $\begin{array}{c}\text { No. of } \\
\text { samples }\end{array}$ & $\begin{array}{c}\text { No. (\%) of samples } \\
\text { with confirmed } \\
\text { S. aureus }\end{array}$ & $\begin{array}{c}\text { No. of S. aureus } \\
\text { isolates }\end{array}$ & $\begin{array}{c}\text { No. (\%) of MRSA } \\
\text { isolates }\end{array}$ \\
\hline A & 147 & $71(48.2 \%)$ & 73 & $1(1.4 \%)$ \\
B & 48 & $19(39.6 \%)$ & 23 & $\mathrm{ND}^{*}$ \\
Total & 195 & $90(46.2 \%)$ & 96 & $1(1 \%)$
\end{tabular}

${ }^{*} N D$ means no detection.

and 19 of 48 (39.6\%) raw milk samples collected from farm A and farm B respectively, were positive for $S$. aureus. Meanwhile, 73 and 23 S. aureus isolates were obtained from samples collected from farm A and farm B, respectively. Additionally, one S. aureus isolate $(1 \%, 1 / 96)$ cultured from farm $\mathrm{A}$ was then identified to harbor the mecA gene, thereby classifying it as a MRSA isolate (Table 2 and Figure 1).

\section{Antimicrobial Susceptibility}

Table 4 shows the antimicrobial susceptibility results for the tested isolates. Of the $96 \mathrm{~S}$. aureus isolates tested, resistance was most frequently observed to penicillin $(31.3 \%, 30 / 96)$, followed by ciprofloxacin $(18.8 \%, 18 / 96)$ and enrofloxacin $(15.6 \%, 15 / 96)$, and to a lesser extent tilmicosin $(6.3 \%, 6 / 96)$, erythromycin $(5.2 \%, 5 / 96)$, gentamycin $(1.0 \%, 1 / 96)$, chloramphenicol $(1.0 \%$, $1 / 96)$, and tetracycline $(1.0 \%, 1 / 96)$. Isolates from farm B showed significantly higher resistance to penicillin $(73.9 \%)$, ciprofloxacin (34.8\%), enrofloxacin (34.8\%), tilmicosin (17.4\%), and erythromycin (17.4\%) than those from farm A $(p<0.05$; Table 4). All $S$. aureus isolates were susceptible to ceftiofur, daptomycin, and vancomycin. Notably, 52 (54.2\%, 52/96) and seven $(7.3 \%, 7 / 96)$ isolates, all of which were cultured from farm A, expressed an intermediate phenotype to ciprofloxacin and enrofloxacin, respectively. Meanwhile, for the top three resistant phenotypes to penicillin, ciprofloxacin, enrofloxacin, the $\mathrm{MIC}_{50}$ and $\mathrm{MIC}_{90}$ were measured at $0.06-$ and $8-\mu \mathrm{g} / \mathrm{mL}$, 2 - and $8-\mu \mathrm{g} / \mathrm{mL}, 0.5$ and $4-\mu \mathrm{g} / \mathrm{mL}$, respectively. Additionally, thirty-seven isolates $(38.5 \%, 37 / 96)$ showed resistant to at least one antimicrobial and 6 isolates $(6.3 \%, 6 / 96)$ showed resistant to $\geq 3$ classes (MDR) (Tables 4, 5 and Figure 1). Totally, nine resistance patterns were identified, wherein PEN $(16.7 \%, 16 / 96)$, PEN-CIP-ENO-ERY-TIL (5.2\%, 5/96) and PEN-CIP-ENO (5.2\%, $5 / 96)$ were the top three frequently identified patterns. Greater diversity among the resistance patterns from farm A (8 patterns) than those from farm B (3 patterns), were noted (Table 5 and Figure 1). PEN-CIP-ENO-ERY-TIL, and PEN were more frequently detected from farm B than from farm A $(p<0.05)$, while PEN-CHL-GEN-TIL, PEN-CIP-ENO, PEN-CIP, CIP, ENO, and TET were only identified in farm A and CIP-ENO only in farm B.

\section{Presence of Virulence and Biofilm Related Genes}

Of the 96 S. aureus isolates tested, 91 (94.8\%) were detected to have one or more virulence genes, and 6 virulence genes ( $t s t, p v l$,

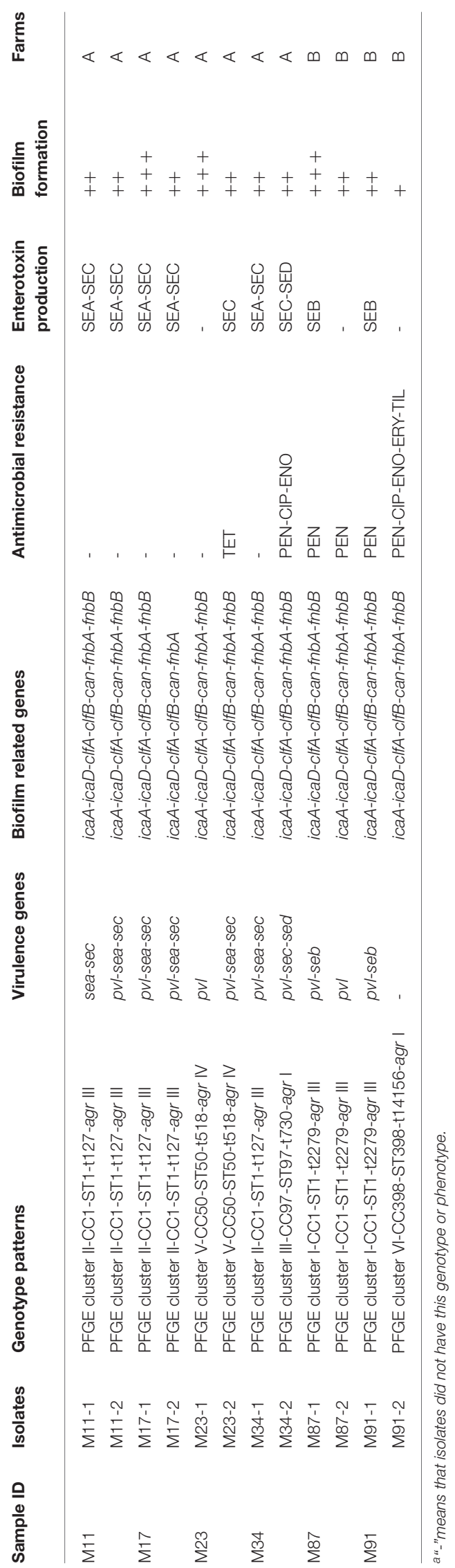




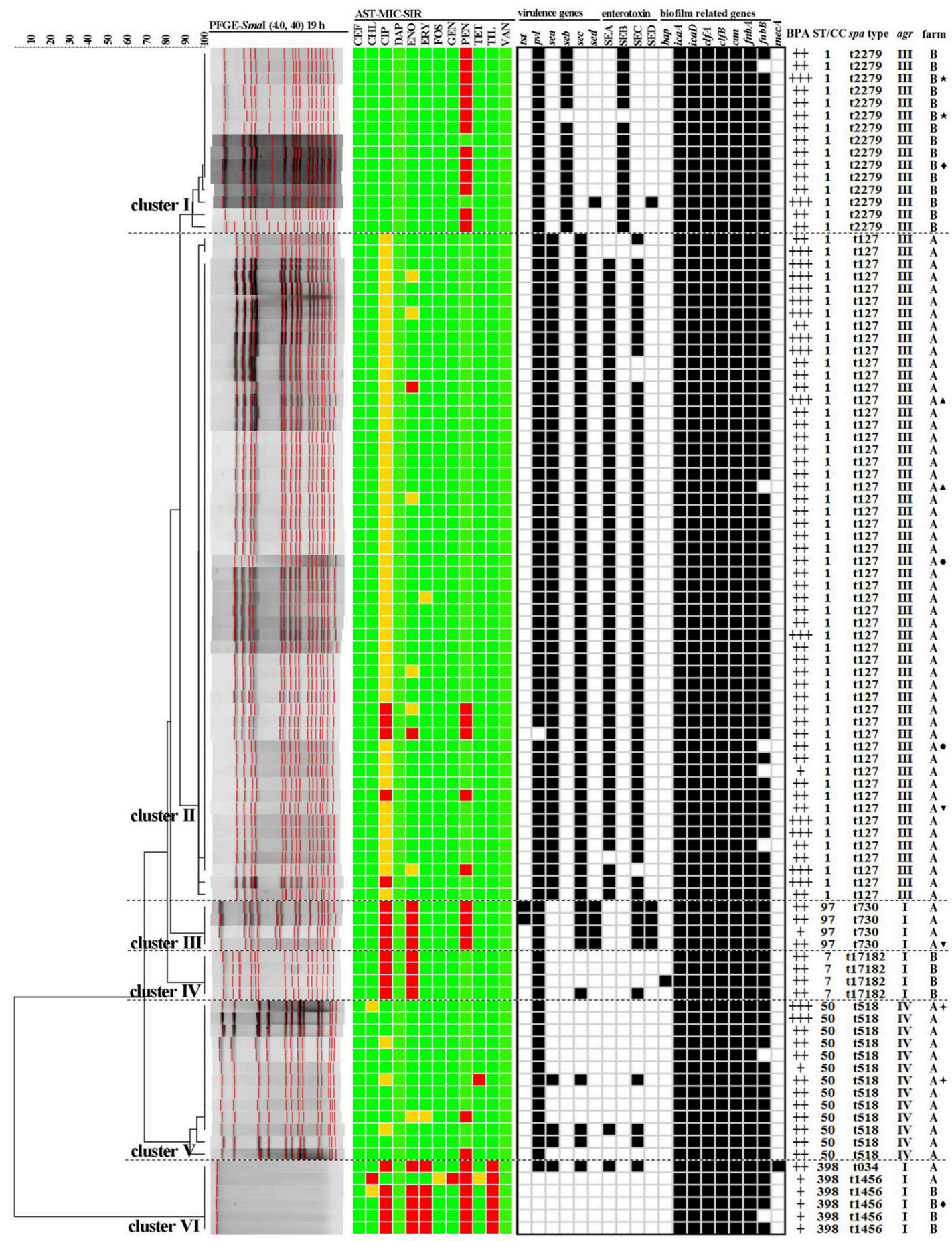

FIGURE 1 | Dendrogram of PFGE patterns and antimicrobial susceptibility testing (AST), virulence genes, enterotoxin production, biofilm and adhesion related genes, mecA gene, and molecular characterization of $96 \mathrm{~S}$. aureus isolates cultured from raw milk in Beijing China. Ninety-six isolates were grouped into 6 clusters (cluster I-VI) by PFGE patterns and all had more than 92\% similarity. The results of AST were showed in different colors according to the MIC values of isolates to different antimicrobial agents. Green squares indicate susceptibility; yellow squares indicate intermediate; and red squares indicate resistance. The detection of virulence genes, enterotoxin production, biofilm and adhesion related genes, and mecA gene were summarized by a heat map. Black squares denote that the studied genes were detected in those isolates, or those isolates could produce those types of enterotoxins. White squares denote that those isolates lack these studied genes or could not produce those types of enterotoxins. BPA represents biofilm production ability. ST/CC represents sequence type of MLST and the clone complex (CC) of this ST. agr represents agr types. Antimicrobial compounds used are abbreviated as follows: TIO, Ceftiofur; CHL, chloramphenicol; CIP, ciprofloxacin; DAP, daptomycin; ENO, enrofloxacin; ERY, erythromycin; FOS, fosfomycin; GEN, gentamycin; PEN, penicillin; TET, tetracycline; TIM, tilmicosin; VAN, vancomycin. The same symbols beside farm number of $\bullet, \mathbf{\Lambda}, \mathbf{\nabla}, \star$, and represent isolates cultured from M11, M17, M23, M34, M87, and M91, respectively. 
TABLE 4 | Antimicrobial susceptibility of the study isolates to eight of the 12 antimicrobial agents tested.

\begin{tabular}{|c|c|c|c|c|c|c|c|c|c|c|c|c|}
\hline \multirow[t]{2}{*}{ Antimicrobials } & \multirow[t]{2}{*}{$\mathrm{MIC}_{50}$} & \multirow[t]{2}{*}{$\mathrm{MIC}_{90}$} & \multirow[t]{2}{*}{ Range } & \multicolumn{3}{|c|}{ Resistant, no. of isolates (\%) } & \multicolumn{3}{|c|}{ Intermediate, no. of isolates (\%) } & \multicolumn{3}{|c|}{ Susceptible, no. of isolates (\%) } \\
\hline & & & & Farm A & Farm B & Total & Farm A & Farm B & Total & Farm A & Farm B & Total \\
\hline Penicillin & 0.06 & 8 & $0.06-32$ & 13(17.8) & $17(73.9)^{\star}$ & 30(31.3) & $\mathrm{O}(0)$ & $\mathrm{O}(0)$ & $\mathrm{O}(0)$ & $60(82.2)$ & $6(26.1)$ & $66(68.8)$ \\
\hline Ciprofloxacin & 2 & 8 & $0.125-16$ & $10(13.7)$ & $8(34.8)^{\star}$ & 18(18.8) & $52(71.2)$ & $0(0)$ & $52(54.2)$ & $11(15.1)$ & 15(65.2) & 26(27.1) \\
\hline Enrofloxacin & 0.5 & 4 & $0.125-32$ & $7(9.6)$ & $8(34.8)^{\star}$ & 15(15.6) & $7(9.6)$ & $\mathrm{O}(0)$ & $7(7.3)$ & $59(80.1)$ & 15(65.2) & $74(77.1)$ \\
\hline Tilmicosin & 2 & 2 & $0.5-64$ & $2(2.7)$ & $4(17.4)^{*}$ & $6(6.3)$ & $\mathrm{O}(0)$ & $\mathrm{O}(0)$ & $\mathrm{O}(0)$ & 71(97.3) & 19(82.6) & 90(93.8) \\
\hline Erythromycin & 0.25 & 0.25 & $0.125-16$ & $1(1.4)$ & $4(17.4)^{\star}$ & $5(5.2)$ & $2(2.7)$ & $\mathrm{O}(0)$ & $2(2.1)$ & 70(95.9) & 19(82.6) & $89(92.7)$ \\
\hline Gentamycin & 1 & 1 & $0.5-64$ & $1(1.4)$ & $O(0)$ & $1(1)$ & $O(0)$ & $O(0)$ & $O(0)$ & 72(98.6) & 23(100) & 95(99) \\
\hline Chloramphenicol & 8 & 8 & $0.5-128$ & $1(1.4)$ & $\mathrm{O}(0)$ & $1(1)$ & $1(1.4)$ & $1(4.3)$ & $2(2.1)$ & 71(97.3) & 22(95.7) & 93(96.9) \\
\hline Tetracycline & 0.5 & 0.5 & $0.25-64$ & $1(1.4)$ & $\mathrm{O}(0)$ & $1(1)$ & $1(1.4)$ & $0(0)$ & $1(1)$ & 71(97.3) & 23(100) & 94(97.9) \\
\hline Fosfomycin & 32 & 64 & $0.5-256$ & $\mathrm{O}(0)$ & $0(0)$ & $\mathrm{O}(0)$ & $1(1.4)$ & $\mathrm{O}(0)$ & $1(1)$ & 72(98.6) & 23(100) & 95(99) \\
\hline Ceftiofur & 0.5 & 2 & $0.25-64$ & $\mathrm{O}(0)$ & $0(0)$ & $\mathrm{O}(0)$ & $\mathrm{O}(0)$ & $\mathrm{O}(0)$ & $\mathrm{O}(0)$ & 73(100) & 23(100) & $96(100)$ \\
\hline Daptomycin & 0.5 & 1 & $0.06-16$ & $\mathrm{O}(0)$ & $0(0)$ & $\mathrm{O}(0)$ & $0(0)$ & $\mathrm{O}(0)$ & $0(0)$ & 73(100) & 23(100) & $96(100)$ \\
\hline Vancomycin & 0.5 & 1 & $0.06-128$ & $\mathrm{O}(0)$ & $O(0)$ & $\mathrm{O}(0)$ & $\mathrm{O}(0)$ & $\mathrm{O}(0)$ & $\mathrm{O}(0)$ & $73(100)$ & 23(100) & $96(100)$ \\
\hline
\end{tabular}

${ }^{*} p<0.05$

sea to sed) were identified with no see genes amplified, by PCR in this study (Table 5 and Figure 1). The 4 SEs genes were detected in $80.2 \%(77 / 96)$ of all 96 isolates. The three most frequently detected virulence genes were $p v l(93.8 \%, 70 / 96)$, sec $(65.6 \%$, $63 / 96)$, and sea $(60.4 \%, 58 / 96)$, followed by seb $(14.6 \%, 14 / 96)$, sed $(5.2 \%, 6 / 96)$, and tst $(2.1 \%, 2 / 96)$. Prevalence rates of the $p v l$ and sec genes from farm A (97.3\% and $84.9 \%$ respectively) were higher than those from farm B (82.6 and $4.3 \%$ respectively) $(p<0.05)$. While, the tst and sea genes were only identified in farm $A$, and the seb gene was only identified in farm B (Table 5). In total, eight different virulence gene patterns were observed. Among all patterns, the $p v l$-sea-sec $(59.4 \%, 57 / 96)$ was common, followed by $p v l(14.6 \%, 14 / 96)$, pvl-seb (13.5\%, 13/96). The $p v l$-sec-sed and tst-pvl-sec-sed patterns were found in $2.1 \%$ (2/96 each) of all 96 isolates, respectively, while pvl-sec, sea-sec, and $p v l$-seb-sed were found in 1\% (1/96 each) of all 96 isolates, respectively (Table 5).

Table 5 lists the biofilm and adhesion related genes of the 96 $S$. aureus isolates recovered from farm $\mathrm{A}$ and farm $\mathrm{B}$. The results show that the $i c a A, i c a D, c l f A, c l f B, c a n$, and $f n b A$ genes were detected in all of the 96 isolates, while 7 isolates ( 5 from farm A and 2 from farm B) did not carry the $f n b B$ gene and the bap gene was only detected in one isolate from farm $B$.

\section{Determination of Enterotoxin Production, and Biofilm Production Ability}

In total, 77 isolates were detected by PCR to have enterotoxin genes, while $53(55.2 \%, 53 / 96), 14$ (14.6\%, 14/96), 59(61.5\%, $59 / 96)$, and $5(5.2 \%, 5 / 96)$ could produce SEA, SEB, SEC, and SED, respectively (Table 5). More than $90 \%$ of the SEs genes harboring S. aureus isolates could produce enterotoxins. Additionally, $54(70.1 \%, 54 / 77)$ isolates simultaneously produced two types of enterotoxins (Table 5 and Figure 1). Moreover, the MRSA isolates harboring sea and sec genes also have the ability to producing both enterotoxins, SEA and SEC.
The microtiter plate assay showed that all 96 S. aureus from the two farms could produce biofilm, although at different intensities (Table 5 and Figure 1). Eight isolates (8.3\%, 8/96), including 4 from farm $\mathrm{A}$ and farm $\mathrm{B}$, were able to produce biofilm weakly; 68 strains $(70.8 \%, 68 / 96)$, including 53 isolates from farm $\mathrm{A}$ and 17 isolates from farm $\mathrm{B}$ respectively, showed moderate biofilm formation; 18 strains $(18.8 \%, 18 / 96)$, including 16 isolates from farm $\mathrm{A}$ and 2 isolates from farm $\mathrm{B}$ respectively, showed strong biofilm formation.

\section{MLST}

All 96 isolates were typed by MLST as shown in Table 5 and Figures 1-3. A total of 5 sequence types (STs) were identified (ST1, ST7, ST50, ST97, and ST398), which were further grouped into 5 CCs. In this study, CC1 was represented by ST1 (CC1ST1) alone, being found as the most predominate sequence type $(71.9 \%, 69 / 96)$ in both two farms, followed by CC50ST50 (13.5\%, 13/96), CC398-ST398 (6.3\%, 6/96), and CC7-ST7 and CC398-ST398 (4.2\%, 4/96 each). The clonal lineages of $S$. aureus isolates were further analyzed based on the sampling farms. As shown in Table 5 and Figure 1, four clonal lineages were identified from farm A, including CC1-ST1, CC50-ST50, CC97-ST97, and CC398-ST398. In contrast, three clonal lineages were identified from farm B, including CC1-ST1, CC7-ST7, and CC398-ST398.

\section{spa Typing}

A total of 7 spa types were obtained in all $96 \mathrm{~S}$. aureus, with 1 novel spa type (t17182) identified (Table 5 and Figure 1). The most prevalent spa type was $t 127(56.3 \%, 54 / 96)$ and this was associated with isolates cultured from farm A. In addition to 127 , four other spa types were also found in isolates from farm A ( $\mathrm{t} 518$, $\mathrm{t} 730, \mathrm{t} 034$, and $\mathrm{t} 14156)$. Meanwhile, Isolates from farm B were defined by 3 spa types, including t2279, t14156, and t17182. Based on MLST, isolates of the sequence types ST7, ST50, and ST97 had their own identical spa types (ST50-t518, ST97-t730, and ST7t17182) (Table 5 and Figures 1, 3). However, there were some 
TABLE 5 | Phenotypes and genotypes of 96 S. aureus isolates tested in this study.

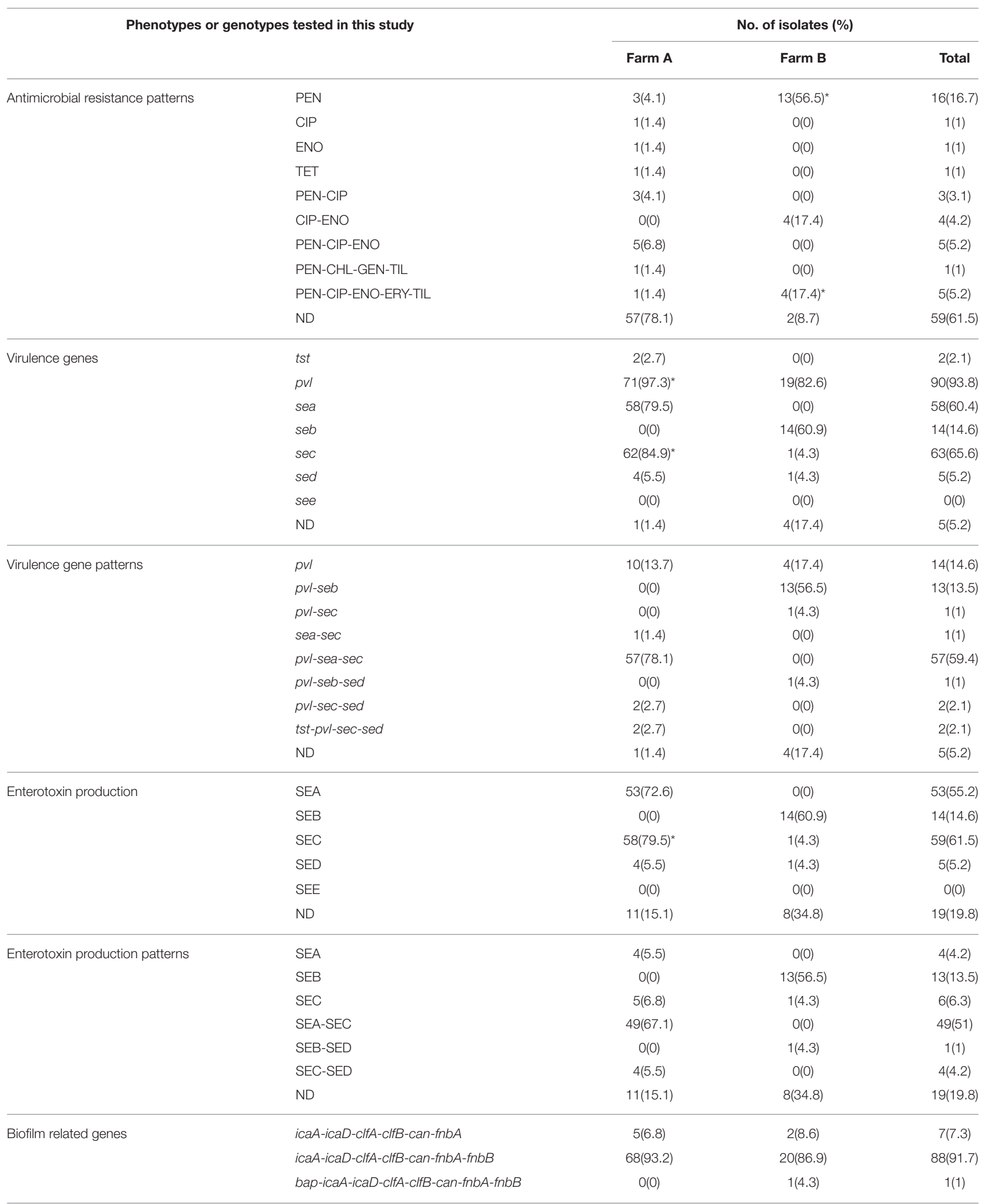


TABLE 5 | Continued

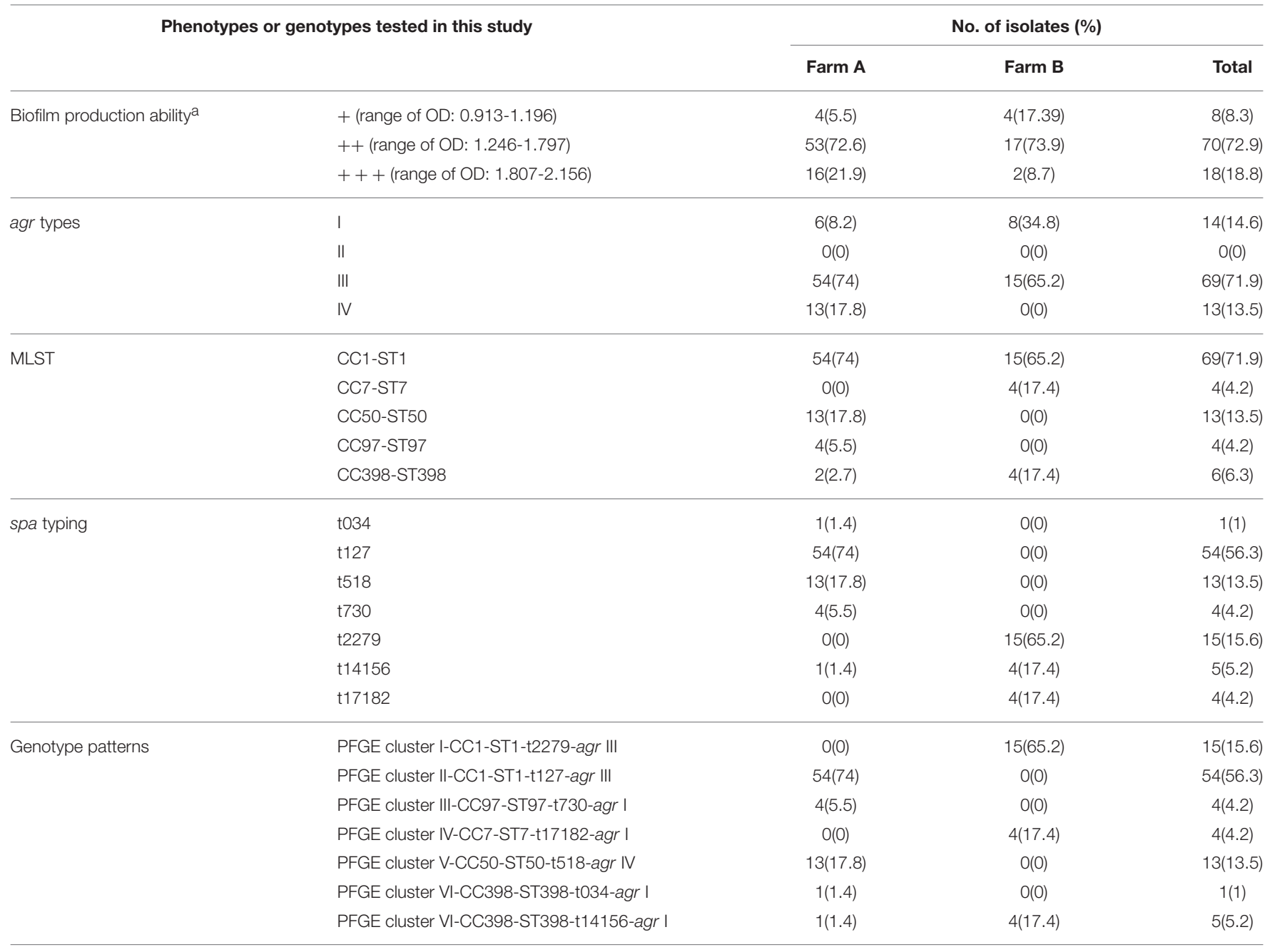

${ }^{a}$ Quantification of biofilm formation by optical density (OD) determination: $(+++)$ : strong biofilm producers $(O D 570>1.8)$, $(++)$ : moderate biofilm producers (1.8 > OD570 > 1.2), (+): weak biofilm producers (1.2 $>$ OD570 $>0.6)$; ${ }^{*} p<0.05$.

exceptions that several isolates owned the identical sequence type but different spa types (ST1-t127/t2279, ST398-t034/t1456) (Table 5 and Figures 1, 3).

\section{agr Genotyping}

The distribution of agr alleles among the 96 isolates is provided in Table 5. Using a multiplex-based PCR, agr alleles were successfully identified in 96 isolates. The agr III genotype was predominant, representing $71.9 \%(69 / 96)$ of the isolates and was the prevailing agr type regardless of the sampling farms of S. aureus isolates, followed by agr I $(14.6 \%, 14 / 96)$ and agr VI (13.5\%, 13/96). No agr II type was detected among all 96 isolates. Furthermore, all 14 isolates with agr I were discriminated into three STs and four spa types (ST7-t17182, ST97-t730, ST398t034, and ST398-t1456). All 69 isolates with agr III with the same sequence type were discriminated into two spa types (ST1t2279 and ST1-t127). However, all 13 isolates with agr IV had the identical sequence type and spa type (ST50-t518) (Table 5 and Figure 1).

\section{PFGE Sub-typing and Identification of Major Clones}

Among 96 isolates subtyped by PFGE, six isolates (belonging to ST398) could not be typed by this method (Table 5 and Figure 1). The other 90 isolates were distinguished into 14 pulso types and then gathered into five PFGE clusters (Cluster I-V) based on more than $92 \%$ genetic similarity. The predominant PFGE cluster was cluster II and included 54 isolates all cultured from farm $\mathrm{A}$, and which were differentiated into 4 pulso types. Fifty of these 54 isolates were found to sharing the same PFGE banding patterns. All isolates in cluster II were characterized as PFGE cluster II-CC1-ST1-t127-agr III. Cluster I included 15 isolates with 5 pulso types and included PFGE Cluster I-CC1ST1-t2279-agr III. All 15 isolates in cluster-I were cultured from farm B. Four isolates from farm A were characterized as PFGE Cluster III-CC97-ST97-t730-agr I, while another 4 isolates from farm A were included in PFGE Cluster III-CC97-ST97-t730-agr I characterized as PFGE Cluster IV-CC7-ST7-t17182-agr I. Cluster $\mathrm{V}$ included 13 isolates with 3 pulso types that were designated 


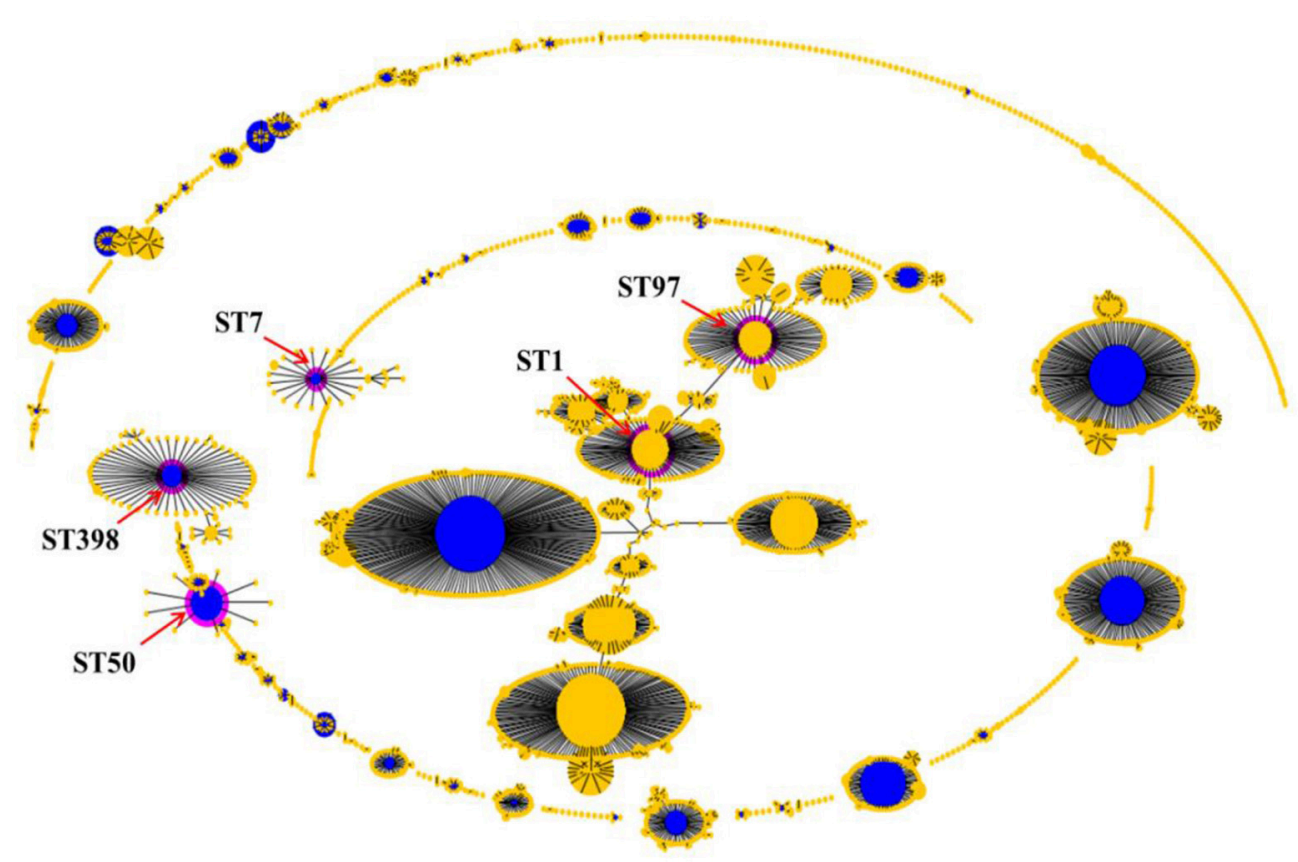

FIGURE 2 | Population snapshot analyses by eBURST on 5779 S. aureus strains that belonged to 2766 STs in S. aureus MLST database. Pink circles labeled with red arrows and the ST names in black font are used for sequence types identified in this study.

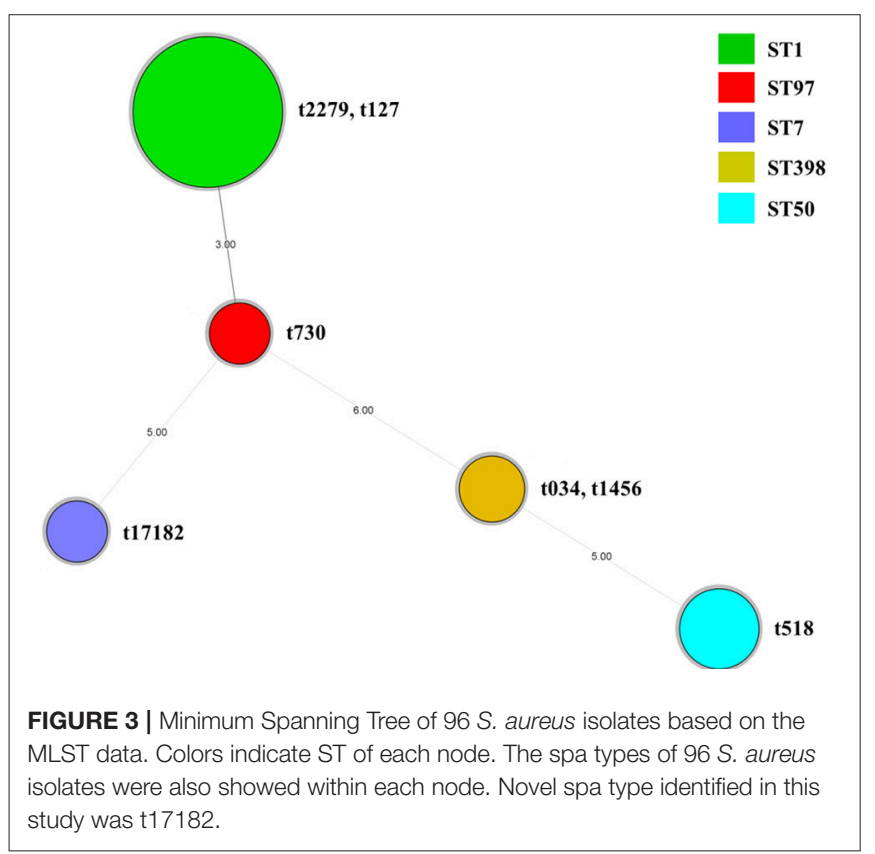

as Cluster V-CC50-ST50-t518-agr IV. Moreover, 6 ST398 isolates that could not be digested with SmaI, were grouped as PFGE cluster VI in this study (Cluster VI-CC398-ST398-t034/t1456agr I). The DI values of PFGE, spa typing, MLST, and agr typing of all 96 isolates were $0.701,0.641,0.463$, and 0.448 , respectively.

\section{Relationship Between Phenotypes and Genotypes}

The relationship between antimicrobial resistance, virulence, biofilm and molecular subtypes is shown in Figure 1. Each clonal complex had specific antimicrobial resistance, virulence, and biofilm characteristics. Isolates identified as CC1-ST1 clones and contained within PFGE cluster I-t2279-agr III were found to be resistance only to PEN with two isolates susceptible to all tested antimicrobial agents tested, followed by three virulence gene patterns denoted as aspvl-seb(13/15), $p v l(1 / 15)$, and $p v l$ seb-sed (1/15). Isolates within PFGE cluster II-CC1-ST1-t127agr III exhibited more resistant diversity including PEN-CIP (3/54), PEN-CIP-ENO (1/54), PEN (1/54), CIP (1/54), ENO (1/54),followed by two virulence gene patterns denoted as $p v l$ sea-sec (53/54) and sea-sec (1/54). All isolates in this cluster were un-susceptible to CIP. All isolates within PFGE cluster III-CC97-ST97-t730-agr I expressed resistance to PEN, CIP, and ENO, followed by two virulence gene patterns, tst-pvl-sec$\operatorname{sed}(2 / 4)$ and $p v l-s e c-s e d(2 / 4)$. The isolates identified as PFGE cluster IV-CC7-ST7-t17182-agr I showed resistant to CIP and ENO, followed by two virulence gene patterns, $p v l(3 / 4)$ and $p v l$ $\sec (1 / 4)$. Only three isolates (3/13) with PFGE cluster V-CC50ST50-t518-agr IV exhibited a resistance phenotype (2 resistant to PEN and 1 resistance to TET) and all 13 isolates in this cluster harbored the $p v l$ gene, with three isolates also carrying the sea and sec genes. In contrast, isolates identified as CC398ST398 expressed the greatest MDR in this study (5 patterns of PEN-CIP-ENO-ERY-TIL and 1 patterns of PEN-CHL-GENTIL). Moreover, the only MRSA isolate with CC398-ST398t034-agr I harbored three virulence genes of pvl, sea and sec, 
whereas another 5 CC398-ST398 isolates identified as t1456agr I were found to carry none of the tested virulence genes. Biofilm formation assay showed that this CC398-ST398-t1456agr I clone was only able to produce biofilm weakly in this study.

\section{DISCUSSION}

S. aureus has been considered as an important cause of zoonotic disease and the potential transmission of MRSA between livestock and humans through close contact, handling and/or consumption of $S$. aureus infected food of animal origin (Kateete et al., 2013; Song et al., 2015; Pereyra et al., 2016). The infection of dairy herds and contamination of raw milk by S. aureus, especially those expressing a MDR phenotype and possessing the ability for produce biofilm and toxins including enterotoxin, TSST-1 and PVL, remains an important public health issue (Cavicchioli et al., 2015; Wang et al., 2016). The public health significance caused by this bacterium is manifested by food-borne poisoning outbreaks caused by dairy products contaminated by $S$. aureus, including one of the largest foodborne outbreaks on record involving 13,420 infected individuals in Japan (Asao et al., 2003; Hennekinne et al., 2012). Of note, food-borne infections attributed to $S$. aureus contaminated dairy foods are also frequently reported in China (Rong et al., 2017). Additionally, the economic cost burden to the dairy farms is considerable; mastitis in dairy cow can result in reductions in milk yield, treatment expense and/or culling in sometimes (Hennekinne et al., 2012). This study investigated the prevalence, genetic diversity, antimicrobial resistance phenotypes, carriage of staphylococcal virulence factors along with testing the capacity of these isolates to produce biofilm and the 5 classical enterotoxins (SEA to SEE). All of these S. aureus were isolated from raw milk samples taken in 2 dairy farms in Beijing, China. Acquisition of the prevalence and characteristics of $S$. aureus isolated from raw milk would be helpful to obtain the antimicrobial resistance and virulence markers as well as predominant clones which can help prevent and control the $S$. aureus contamination in dairy herd and protect the end consumer.

In the present study, $46.2 \%(90 / 195)$ of raw milk samples taken from dairy cows with mastitis were positive for $S$. aureus. This prevalence is similar to a recent report in China and other reports in Brazil and Italy (Cavicchioli et al., 2015; Li et al., 2015; Giacinti et al., 2017). However, another recent study reported that the prevalence of $S$. aureus in raw milk of health cows in Beijing was 22.0\% (Liu et al., 2017). Overall, our data indicate that $S$. aureus is common and frequently detected in the raw milk of dairy cows with mastitis in Beijing, China. Further research is needed to explore methods of controlling $S$. aureus occurrence in raw milk.

In recent years, the emergence of MDR $S$. aureus, particularly MRSA, leading to animal and human infections, has become a growing public health concern (Li et al., 2015). In the current study, few resistances were detected among all 96 S. aureus (38.5\% resistant to at least one antimicrobial), which were similar to those in Italy $(39.4 \%)$ and Poland (23\%), but much lower than two previous reports in Chinese $(87 \%$ and $72.2 \%$, respectively) and those in India (95\%) (Li et al., 2015; Rola et al., 2015; Mistry et al., 2016; Giacinti et al., 2017; Liu et al., 2017). Moreover, only 6 isolates (6.3\%) showed MDR that was lower than reports in other regions in China (Li et al., 2015; Liu et al., 2017). According to previous studies, penicillinresistant $S$. aureus are the most prevalence isolates among raw milk and ranged from less than $10 \%$ to over $80 \%$ ( $\mathrm{Li}$ et al., 2015; Rola et al., 2015; Liu et al., 2017). In this study, 31.3\% of $S$. aureus were resistant to this antimicrobial agent. It was notable that ciprofloxacin- and enrofloxacin-resistant $S$. aureus were found to be the next most frequently detected resistance types in addition to penicillin. Both are fluoroquinolones, wherein ciprofloxacin a third generation fluoroquinolone is used at clinical level while enrofloxacin is specially used for veterinary applications in China (Hoang et al., 2017; Li J. et al., 2017). Once human and/or animals become infected with these resistant isolates, treatment failure using these two antimicrobials, is inevitable. Additionally, 54.2 and $7.3 \%$ of the isolates from farm A expressed an intermediate phenotype to ciprofloxacin and enrofloxacin, respectively. Meanwhile, isolates from farm $B$ exhibited significantly higher resistance to a panel of antimicrobial compounds including penicillin, ciprofloxacin, enrofloxacin, tilmicosin, and erythromycin when compared to those from farm A $(p<0.05)$. Moreover, the resistance patterns were different between two farms in that PEN-CIP-ENO-ERYTIL and PEN were more frequently detected from farm B compared with farm A $(p<0.05)$. These results suggested that the isolates from both farms may have their own resistance characteristics and the resistance patterns from farm A were more diverse than those from farm B $(p<0.05)$. Furthermore, it has been reported that rational management and appropriate usage of antimicrobial compounds in food-producing livestock is very important to control and prevent the spread of drugresistant isolates (Jessen et al., 2017). All isolates in this study exhibited low-level resistance to other antimicrobial agents tested and similarly the $\mathrm{MIC}_{50}$ and $\mathrm{MIC}_{90}$ values were relatively low, a situation that is much different to previous reports in China and other countries (Li et al., 2015; Mistry et al., 2016; Liu et al., 2017). The relatively low rate of resistance and MDR isolates observed in this study could be due to the extensive farming systems and the strict management of the use of antimicrobial agents by the company.

MRSA is considered as major cause of hospital-acquired and community-acquired infections (Gopal and Divya, 2017). Additionally, the contaminated animal and associated products have been supposed to be a potential source of communityacquired MRSA (Gopal and Divya, 2017). Recently, the isolation of MRSA from raw milk and dairy products has been reported worldwide (Rola et al., 2016; Tarekgne et al., 2016; Basanisi et al., 2017). In this study, one $S$. aureus isolate $(1.4 \%, 1 / 96)$ was identified as MRSA being confirmed by amplifying the mecA gene. The current study's prevalence reported for MRSA is lower than those reported previously in China or India (4.8-48.7\%) (Li et al., 2015; Mistry et al., 2016; Liu et al., 2017). However, the potential MRSA transmission risk via the food chain, particularly by insufficient pasteurization milk, cannot be ignored. 
With regard to the risk of pathogenicity, the presence of virulence genes among all 96 isolates was also assessed in this study. The classic enterotoxin SE determinants, of $S$. aureus are known to cause sporadic food-poisoning incidents or even foodborne outbreaks. It is reported that $89.7 \%$ isolates from cow milk related to mastitis carried one or more SEs genes (Song et al., 2015). In the current study, $80.2 \%$ of the isolates were positive for SE encoding genes and the sec (65.6\%) and sea (60.4\%) genes were the most frequently detected. This finding is similar to those in previous reports from China and Australia, whereas the sed gene was mainly detected among isolates from raw milk samples in Poland (Rola et al., 2015; Song et al., 2015; McMillan et al., 2016; Liu et al., 2017). Meanwhile, another Chinese study reported that the seb gene was the most commonly detected (Cheng et al., 2016). Additionally, the prevalence rates of the sec gene from farm A (84.9\%) was higher than from farm B (4.3\%) $(p<0.05)$. While, the sea gene was only found in farm $A$, and the seb gene was only found in farm B. Therefore, the different prevalence rates observed among all SE genes could be due to the fact that these isolates originated in geographically diverse locations. According to previous reports, the see gene was rarely present in raw milk or even retail food in China, and similarly, this marker was not detected in this study. Notably, the pvl-encoding gene showed a very high prevalence $(93.8 \%)$ in the tested isolates, which was similar to previous reports (Esposito et al., 2013; Aires-de-Sousa, 2017). It was reported that the $p v l$-encoding gene were present at a high prevalence among methicillin-sensitive isolates and the Livestock-associated MRSA (LA-MRSA) isolates positive with PVL mostly originated from humans (Price et al., 2012; Wardyn et al., 2012). Two isolates in this study were identified to have the tst gene, which could cause severe clinical diseases (Xie et al., 2011). Our data highlight the necessity to identify virulence factors among pathogenic S. aureus.

Several studies examined for the presence of SEs genes among S. aureus cultured from raw milk and their food products (Asao et al., 2003; Song et al., 2015; Cheng et al., 2016; Liu et al., 2017). However, few reports assessed the enterotoxin producing capacity of these isolates in China. To our best knowledge, this study firstly reported the production of 4 classic SEs in raw dairy milk in China. The results showed that $>90 \%$ of the SEs (sea to sed) genes carried $S$. Aureus isolates could produce enterotoxins. Additionally, $54(70.1 \%, 54 / 77)$ of the SE gene carrying S. aureus simultaneously produced two types of enterotoxins, including one MRSA isolate (positive for SEA and SEC). Once enterotoxins were already produced, and these can generally retain their biological activity even after heat treatment (Cavicchioli et al., 2015). Thus, it is necessary to develop measures to eliminate the contamination of this bacterium in dairy products.

The study also investigated the distribution of biofilm and adhesion related genes among all isolate, some of which are also related to bacterial virulence (Rasmussen et al., 2013). In this study, all 96 isolates harbored the icaAD, fnbA, clf $A B$, and cna genes and $92.7 \%$ of the isolates harbored the $f n b B$ gene. In contrast the bap gene was only detected in one isolate. Thus, these isolates have the ability to form biofilm a feature that suggests these bacteria have the potential to persist in this environment. The ability to form biofilms helps $S$. aureus to persist in infections and subclinical and clinical cases of bovine mastitis (Dhanawade et al., 2010). In the present study all $96 \mathrm{~S}$. aureus isolates could form biofilms as determined by the microtiter plate assay described above, and these findings agree with a previous report from Argentina but being higher in number than reported in a similar study from Brazil (Lee et al., 2014; Pereyra et al., 2016). The high incidence of biofilm-producing $S$. aureus isolates in this study suggests the necessary for dairy farms to improve the quality assurance systems, in order to decrease and eliminate these isolates.

Our data also highlighted the diverse genetic backgrounds of the S. aureus from raw milk by MLST, spa typing, agr typing and PFGE sub-typing. Since the MLST genotyping for $S$. aureus was first reported, it has been widely used in epidemiological analysis of $S$. aureus infection and associated food poisoning outbreaks (Enright et al., 2000). In this study, five sequence types were obtained by MLST and each was further grouped into a clonal complexes. CC1-ST1 was the predominant clone $(71.9 \%, 69 / 96)$, followed by CC50-ST50, CC398-ST398, CC7-ST7, and CC398-ST398, all of which have been reported in raw milk in China, previously (Song et al., 2015). Moreover, the ST1 and ST97 lineages were also detected frequently from bovine milk worldwide, while ST398, the most common livestock-associated MRSA type, has been already found in both food-producing animal and human species (Mistry et al., 2016; Gopal and Divya, 2017). Six isolates were identified as ST398 including the only one detected as a MRSA strain in this study. It was reported that MRSA ST398 is the most prevalent clone in Europe and North America, whereas methicillin-susceptible S. aureus (MSSA) ST398 was predominant in Asian regions (Asai et al., 2012; Yan et al., 2014). In total, six known spa types (t034, t127, t518, t730, t1456, and t2279) and 1 newly identified spa type (t17182) were identified in this study. A previous study also observed spa diversity among the STs although some spa types corresponded with either an ST or a CC (Chao et al., 2015). The spa types, t127 and t2279, have been reported as communityassociated clones previously, and these were the top two frequently distributed genotypes among raw milk samples where all isolates of both types were identified as ST1 (Song et al., 2015). Considering the transmission of bacterial species between humans and livestock is increasingly being detected in farm workers in several countries (Huijsdens et al., 2006; Kateete et al., 2013), a recent study showed that the 127 clone could be present in cows, humans and environments (Papadopoulos et al., 2018). Although isolates of this spa type exhibited less antimicrobial resistance in this study, the potential of biofilm and enterotoxin producing would lead to persistent existence and subsequent contamination. Therefore, this clone could be important source of contaminations in cow farms, leading to quickly spread and large infections in both dairy herd and human community.

Isolates of ST398 types corresponded to one t034 (MRSA) and 5 to t1456 (MSSA) along with each of the other STs being linked to sole spa type. Of note, the ST398-t1456 MSSA was firstly 
identified in China, while the ST398-t1456 clone was related to LA-MRSA in Europe (Köck et al., 2013). Furthermore, the newly identified spa type t17182 corresponded to ST7, which has been reported to be related to bovine mastitis ( $\mathrm{Li} \mathrm{T}$. et al., 2017). Moreover, ST50-t518 found in this study was reported to be mainly present in bovines in Denmark (Hasman et al., 2010). The other spa type t730, has been less frequently detected then before, and corresponded to the bovine milk-associated sequence type ST97 (Gopal and Divya, 2017). In this study agr type III was the most predominant agr type (71.9\%) among S. aureus isolates, which is in accordance with a previous report from Brazil (48.2\%) (Silva et al., 2013). However, agrI and agr II could be predominant types according to previous reports (Fabres-Klein et al., 2015; Khoramrooz et al., 2016; Mistry et al., 2016). Only 14.6 and $13.5 \%$ of our isolates were identified as agr I and IV respectively, which are lower than previous reports (Fabres-Klein et al., 2015; Mistry et al., 2016). Similar to other studies the agr II was not identified in the current study (Fabres-Klein et al., 2015; Khoramrooz et al., 2016; Mistry et al., 2016).

PFGE is generally recognized as the current gold standard method, and it has been widely used in genotyping of various bacteria including bovine mastitis associated S. aureus (De Oliveira et al., 2000; McMillan et al., 2016). Previous studies demonstrated that different clonal lineages may exhibit specific patterns of antimicrobial resistance and contain various virulence factors (Hata et al., 2010; Song et al., 2015). In this study, isolates of the PFGE cluster II (56.3\%) and cluster I (15.6\%) were the most frequently detected. All belonged to ST1 (CC1), t127/2279 along with the agr type or agr III which were grouped in these two clusters. The agr system is related to the regulation of virulence factors and different agr groups may have specific virulence patterns (Melchior et al., 2009; Khoramrooz et al., 2016). This study showed that isolates of agr III of represented by two clones (PFGE Cluster I/II-CC1-ST1-t127/2279), carried more virulence genes than those of $a g r$ I and $a g r$ IV types, suggesting that agr profiles may be associated with the virulence potential of $S$. aureus. Furthermore, isolates in PFGE Cluster II-CC1ST1-t127-agr III exhibited the most diversities of antimicrobial resistant, while isolates in PFGE Cluster I-CC1-ST1-t2279-agr III was only resistant to PEN. Of note, the 5 MSSA-ST398t1456-agr I isolates expressed the most MDR patterns but with no virulence genes and showed weakly biofilm formation, whereas the MRSA-ST398-t034-agr I clone expressed MDR and virulence $(p v l-s e a-s e c)$ as well as showing moderate biofilm formation in this study. All isolates within PFGE cluster IIICC97-ST97-t730-agr I clone were resistant to PEN, CIP, and ENO, while all isolates in the PFGE cluster IV-CC7-ST7-t17182agr I showed resistant to CIP and ENO. Geographically, isolates from farm A and farm B were well distinguished phylogenetically in this study. It is interesting that we found different isolates from the same mastitic milk sample that showed different genotypes or phenotypes in this study, which confirmed the fact that different clones could colonize in one host, making it harder to eliminate and control $S$. aureus infections in dairy cows.

\section{CONCLUSIONS}

In summary, our research provides detailed epidemiological survey on the prevalence of $S$. aureus in raw milk of dairy cows with mastitis in Beijing, China. This study demonstrated a rather high prevalence of $S$. aureus with enterotoxigenic and biofilm forming abilities that may contribute to $S$. aureus persisting in the dairy farms leading to severe infections and subsequent food poisoning. To the best of our knowledge, this study firstly reported the classic SEs production in raw milk from cows in China. However the percentage of MDR and MRSA isolates was low in this study, their pathogenicity and transmission risk cannot be ignored. Of note, it is necessary to control and eliminate the present of MDR, enterotoxigenic and biofilm formatting $S$. aureus in raw milk. Additionally, our study also demonstrated the genetic diversity these isolates. Results of the present study highlight the dominant genetic lineages of livestock associated found not only in China but also worldwide. Although new spa type variants were found, their lineage related sequence type suggested that these strains may also associate with bovine mastitis. Significant differences genetic diversity along with antimicrobial resistance, virulence factors and biofilm formation were observed for $S$. aureus isolates from raw milk. It was shown that $S$. aureus with similar genetic characteristic displayed specific antimicrobial resistance patterns, virulence gene profiles, biofilm formations and geographic features and different clones could colonize in one dairy host. Therefore, monitoring the genotypes of $S$. aureus in dairy cow would give assistance to distinguish prevalent clones, which can help dairy farms develop control measures for mastitis caused by S. aureus.

\section{AVAILABILITY OF DATA AND MATERIALS}

The aggregate data supporting findings contained within this manuscript will be shared upon request submitted to the corresponding author.

\section{AUTHOR CONTRIBUTIONS}

WW, ZB, XL, FL, and SF designed experiments. TJ, ZP, JX, and LY carried out experiments. WW and XL analyzed experimental data. WW, ZB, FL, and SF wrote the manuscript.

\section{FUNDING}

This study was funded by the National Key R\&D Program of China (2016YFD0401102), and China Food Safety Talent Competency Development Initiative: CFSA 523 Program.

\section{ACKNOWLEDGMENTS}

We sincerely thank all the participants who took part in this study. 


\section{REFERENCES}

Aires-de-Sousa, M. (2017). Methicillin-resistant Staphylococcus aureus among animals: current overview. Clin. Microbiol. Infect. 23, 373-380. doi: 10.1016/j.cmi.2016.11.002

Asai, T., Hiki, M., Baba, K., Usui, M., Ishihara, K., and Tamura, Y. (2012). Presence of Staphylococcus aureus ST398 and ST9 in swine in Japan. Jpn. J. Infect. Dis. 65, 551-552. doi: 10.7883/yoken.65.551

Asao, T., Kumeda, Y., Kawai, T., Shibata, T., Oda, H., Haruki, K., et al. (2003). An extensive outbreak of staphylococcal food poisoning due to lowfat milk in Japan: estimation of enterotoxin A in the incriminated milk and powdered skim milk. Epidemiol. Infect. 130, 33-40. doi: 10.1017/S09502688020 07951

Basanisi, M. G., La Bella, G., Nobili, G., Franconieri, I., and La Salandra, G. (2017). Genotyping of methicillin-resistant Staphylococcus aureus (MRSA) isolated from milk and dairy products in South Italy. Food Microbiol. 62, 141-146. doi: 10.1016/j.fm.2016.10.020

Bergdoll, M. S., Crass, B. A., Reiser, R. F., Robbins, R. N., and Davis, J. P. (1981). A new staphylococcal enterotoxin, enterotoxin F, associated with toxic-shock-syndrome Staphylococcus aureus isolates. Lancet 1, 1017-1021 doi: 10.1016/S0140-6736(81)92186-3

Cavicchioli, V. Q., Scatamburlo, T. M., Yamazi, A. K., Pieri, F. A., and Nero, L. A. (2015). Occurrence of Salmonella, Listeria monocytogenes, and enterotoxigenic Staphylococcus in goat milk from small and medium-sized farms located in Minas Gerais State, Brazil. J. Dairy. Sci. 98, 8386-8390. doi: 10.3168/jds.2015-9733

Chao, G., Bao, G., Cao, Y., Yan, W., Wang, Y., Zhang, X., et al. (2015). Prevalence and diversity of enterotoxin genes with genetic background of Staphylococcus aureus isolates from different origins in China. Int. J. Food Microbiol. 211, 142-147. doi: 10.1016/j.ijfoodmicro.2015.07.018

Cheng, J., Wang, Y., Cao, Y., Yan, W., Niu, X., Zhou, L., et al. (2016). The Distribution of 18 enterotoxin and enterotoxin-like genes in Staphylococcus aureus strains from different sources in East China. Foodborne Pathog. Dis. 13, 171-176. doi: 10.1089/fpd.2015.1963

CLSI (2015). Methods for Antimicrobial Dilution and Disk Susceptibility Testing of Infrequently Isolated or Fastidious Bacteria; Approved Guideline. Wayne; Pennsylvania, PA: Clinical Laboratory Standards Institute.

Darwish, S. F., and Asfour, H. A. (2013). Investigation of biofilm forming ability in Staphylococci causing bovine mastitis using phenotypic and genotypic assays. Scientific World J. 2013, 378492. doi: 10.1155/2013/378492

De Oliveira, A. P., Watts, J. L., Salmon, S. A., and Aarestrup, F. M. (2000). Antimicrobial susceptibility of Staphylococcus aureus isolated from bovine mastitis in Europe and the United States. J. Dairy Sci. 83, 855-862. doi: 10.3168/jds.S0022-0302(00)74949-6

Dhanawade, N. B., Kalorey, D. R., Srinivasan, R., Barbuddhe, S. B., and Kurkure, N. V. (2010). Detection of intercellular adhesion genes and biofilm production in Staphylococcus aureus isolated from bovine subclinical mastitis. Vet. Res. Commun. 34, 81-89. doi: 10.1007/s11259-009-9326-0

Dufour, S., Dohoo, I. R., Barkema, H. W., Descôteaux, L., Devries, T. J., Reyher, K. K., et al. (2012). Manageable risk factors associated with the lactational incidence, elimination, and prevalence of Staphylococcus aureusintramammary infections in dairy cows. J. Dairy Sci. 95, 1283-1300. doi: 10.3168/jds.20 11-4711

Enright, M. C., Day, N. P., Davies, C. E., Peacock, S. J., and Spratt, B. G. (2000). Multilocus sequence typing for characterization of methicillin-resistant and methicillin-susceptible clones of Staphylococcus aureus. J. Clin. Microbiol. 38, 1008-1015. doi: 10.1128/JCM.02421-12

Esposito, S., Purrello, S. M., Bonnet, E., Novelli, A., Tripodi, F., Pascale, R., et al. (2013). Central venous catheter-related biofilm infections: an up-to-date focus on meticillin-resistant Staphylococcus aureus. J. Glob. Antimicrob. Resist. 1, 71-78. doi: 10.1016/j.jgar.2013.03.002

Fabres-Klein, M. H., Caizer Santos, M. J., Contelli Klein, R., Nunes de Souza, G., and de Oliveira Barros Ribon, A. (2015). An association between milk and slime increases biofilm production by bovine Staphylococcus aureus. BMC Vet. Res. 11, 3. doi: 10.1186/s12917-015-0319-7

Feil, E. J., Li, B. C., Aanensen, D. M., Hanage, W. P., and Spratt, B. G. (2004). eBURST: inferring patterns of evolutionary descent among clusters of related bacterial genotypes from multilocus sequence typing data. J. Bacteriol. 186, 1518-1530. doi: 10.1128/JB.186.5.1518-1530.2004

Felipe, V., Morgante, C. A., Somale, P. S., Varroni, F., Zingaretti, M. L., Bachetti, R. A., et al. (2017). Evaluation of the biofilm forming ability and its associated genes in Staphylococcus species isolates from bovine mastitis in Argentinean dairy farms. Microb. Pathog. 104, 278-286. doi: 10.1016/j.micpath.2017.01.047

Giacinti, G., Carfora, V., Caprioli, A., Sagrafoli, D., Marri, N., Giangolini, G., et al. (2017). Prevalence and characterization of methicillin-resistant Staphylococcus aureus carrying mecA or mecC and methicillin-susceptible Staphylococcus aureus in dairy sheep farms in central Italy. J. Dairy Sci. 100, 7857-7863. doi: 10.3168/jds.2017-12940

Gomes, F., and Henriques, M. (2016). Control of bovine mastitis: old and recent therapeutic approaches. Curr. Microbiol. 72, 377-382. doi: 10.1007/s00284-015-0958-8

Gopal, S., and Divya, K. C. (2017). Can methicillin-resistant Staphylococcus aureus prevalence from dairy cows in India act as potential risk for community-associated infections? A review. Vet. World. 10, 311-318. doi: 10.14202/vetworld.2017.311-318

Harmsen, D., Claus, H., Witte, W., Rothgänger, J., Claus, H., Turnwald, D., et al. (2003). Typing of methicillin-resistant Staphylococcus aureus in a university hospital setting by using novel software for spa repeat determination and database management. J. Clin. Microbiol. 41, 5442-5448. doi: 10.1128/JCM.41.12.5442-5448.2003

Hasman, H., Moodley, A., Guardabassi, L., Stegger, M., Skov, R. L., and Aarestrup, F. M. (2010). Spa type distribution in Staphylococcus aureus originating from pigs, cattle and poultry. Vet. Microbiol. 141, 326-331. doi: 10.1016/j.vetmic.2009.09.025

Hata, E., Katsuda, K., Kobayashi, H., Uchida, I., Tanaka, K., and Eguchi, M. (2010). Genetic variation among Staphylococcus aureus strains from bovine milk and their relevance to methicillin-resistant isolates from humans. J. Clin. Microbiol. 48, 2130-2139. doi: 10.1128/JCM.01940-09

Hennekinne, J. A., De Buyser, M. L., and Dragacci, S. (2012). Staphylococcus aureus and its food poisoning toxins: characterization and outbreak investigation. FEMS Microbiol. Rev. 36, 815-836. doi: 10.1111/j.1574-6976.2011.00311.x

Hoang, P. H., Awasthi, S. P., DO Nguyen, P., Nguyen, N. L., Nguyen, D. T., LE, N. H., et al. (2017). Antimicrobial resistance profiles and molecular characterization of Escherichia coli strains isolated from healthy adults in Ho Chi Minh City, Vietnam. J. Vet. Med. Sci. 79, 479-485. doi: 10.1292/jvms.16-0639

Huijsdens, X. W., van Dijke, B. J., Spalburg, E., van Santen-Verheuvel, M. G., Heck, M. E., Pluister, G. N., et al. (2006). Community-acquired MRSA and pigfarming. Ann. Clin. Microbiol. Antimicrob. 5:26. doi: 10.1186/1476-0711-5-26

Jakobsen, R. A., Heggebø, R., Sunde, E. B., and Skjervheim, M. (2011). Staphylococcus aureus and Listeria monocytogenes in Norwegian raw milk cheese production. Food Microbiol. 28, 492-496. doi: 10.1016/j.fm.2010.10.017

Jans, C., Merz, A., Johler, S., Younan, M., Tanner, S. A., Kaindi, D. W. M., et al. (2017). East and West African milk products are reservoirs for human and livestock-associated Staphylococcus aureus. Food Microbiol. 65, 64-73. doi: 10.1016/j.fm.2017.01.017

Jarraud, S., Mougel, C., Thioulouse, J., Lina, G., Meugnier, H., Forey, F., et al. (2002). Relationships between S. aureus genetic background, virulence factors, agrgroups (Allele), and human disease. Infect. Immun. 70, 631-641. doi: 10.1128/IAI.70.2.631-641.2002

Jessen, L. R., Sørensen, T. M., Lilja, Z. L., Kristensen, M., Hald, T., and Damborg, P. (2017). Cross-sectional survey on the use and impact of the Danish national antibiotic use guidelines for companion animal practice. Acta. Vet. Scand. 59, 81. doi: 10.1186/s13028-017-0350-8

Johler, S.,Weder, D.,Bridy, C.,Huguenin, M. C., Robert, L., Hummerjohann, J., et al. (2015). Outbreak of staphylococcal food poisoning among children and staff at a Swiss boarding school due to soft cheese made from raw milk. J. Dairy Sci. 98, 2944-2948. doi: 10.3168/jds.2014-9123

Kateete, D. P., Kabugo, U., Baluku, H., Nyakarahuka, L., Kyobe, S., Okee, M., et al. (2013). Prevalence and antimicrobial susceptibility patterns of bacteria from milkmen and cows with clinical mastitis in and around Kampala, Uganda. PLoS ONE 8:e63413. doi: 10.1371/journal.pone.0063413

Khoramian, B., Jabalameli, F., Niasari-Naslaji, A., Taherikalani, M., and Emaneini, M. (2015). Comparison of virulence factors and biofilm formation among 
Staphylococcus aureus strains isolated from human and bovine infections. Microb. Pathog. 88, 73-77. doi: 10.1016/j.micpath.2015.08.007

Khoramrooz, S. S., Mansouri, F., Marashifard, M., Malek Hosseini, S. A., Akbarian Chenarestane-Olia, F., Ganavehei, B., et al. (2016). Detection of biofilm related genes, classical enterotoxin genes and agr typing among Staphylococcus aureus isolated from bovine with subclinical mastitis in southwest of Iran. Microb. Pathog. 97, 45-51. doi: 10.1016/j.micpath.2016.05.022

Klein, R. C., Fabres-Klein, M. H., Brito, M. A., Fietto, L. G., and Ribon Ade, O. (2012). Staphylococcus aureus of bovine origin: genetic diversity, prevalence and the expression of adhesin-encoding genes. Vet. Microbiol. 160, 183-188. doi: 10.1016/j.vetmic.2012.05.025

Köck, R., Schaumburg, F., Mellmann, A., Köksal, M., Jurke, A., Becker, K., et al. (2013). Livestock-associated methicillin-resistant Staphylococcus aureus (MRSA) as causes of human infection and colonization in Germany. PLoS ONE 8:e55040. doi: 10.1371/journal.pone.0055040

Lee, S. H., Mangolin, B. L., Gonçalves, J. L., Neeff, D. V., Silva, M. P., Cruz, A. G., et al. (2014). Biofilm-producing ability of Staphylococcus aureus isolates from Brazilian dairy farms. J. Dairy Sci. 97, 1812-1816. doi: 10.3168/jds.2013-7387

Li, J., Hao, H., Cheng, G., Liu, C., Ahmed, S., Shabbir, M. A. B., et al. (2017). Microbial shifts in the intestinal microbiota of Salmonella infected chickens in response to enrofloxacin. Front. Microbiol. 8:1711. doi: 10.3389/fmicb.2017.01711

Li, L., Zhou, L., Wang, L., Xue, H., and Zhao, X. (2015). Characterization of methicillin-resistant and -susceptible staphylococcal isolates from bovine milk in northwestern China. PLOS ONE 10:e116699. doi: 10.1371/journal.pone.0116699

Li, T., Lu, H., Wang, X., Gao, Q., Dai, Y., Shang, J., et al. (2017). Molecular characteristics of Staphylococcus aureus causing bovine mastitis between 2014 and 2015. Front. Cell Infect. Microbiol. 7:127. doi: 10.3389/fcimb.2017.00127

Liu, H., Li, S., Meng, L., Dong, L., Zhao, S., Lan, X., et al. (2017). Prevalence, antimicrobial susceptibility, and molecular characterization of Staphylococcus aureus isolated from dairy herds in northern China. J. Dairy Sci. 100, 8796-8803. doi: 10.3168/jds.2017-13370

McClure, J. A., Conly, J. M., Lau, V., Elsayed, S., Louie, T., Hutchins, W., et al. (2006). Novel multiplex PCR assay for detection of the staphylococcal virulence marker Panton-Valentine leukocidin genes and simultaneous discrimination of methicillin-susceptible from -resistant staphylococci. $J$ ClinMicrobiol. 44, 1141-1144. doi: 10.1128/JCM.44.3.1141-1144.2006

McMillan, K., Moore, S. C., McAuley, C. M., Fegan, N., and Fox, E. M. (2016). Characterization of Staphylococcus aureus isolates from raw milk sources in Victoria, Australia. BMC Microbiol. 16, 169. doi: 10.1186/s12866-016-0789-1

Melchior, M. B., van Osch, M. H., Graat, R. M., van Duijkeren, E., Mevius, D. J., Nielen, M., et al. (2009). Biofilm formation and genotyping of Staphylococcus aureus bovine mastitis isolates: evidence for lack of penicillin-resistance in Agrtype II strains. Vet. Microbiol. 137, 83-89. doi: 10.1016/j.vetmic.2008.12.004

Mistry, H., Sharma, P., Mahato, S., Saravanan, R., Kumar, P. A., and Bhandari, V. (2016). Prevalence and characterization of oxacillin susceptible mecA-positive clinical isolates of Staphylococcus aureus causing bovine mastitis in India. PLoS ONE 11:e0162256. doi: 10.1371/journal.pone.0162256

Murakami, K., Minamide, W., Wada, K., Nakamura, E., Teraoka, H., and Watanabe, S. (1991). Identification of methicillin-resistant strains of staphylococci by polymerase chain reaction. J. Clin. Microbiol. 29, 2240-2244.

Murchan, S., Kaufmann, M. E., Deplano, A., de Ryck, R., Struelens, M., Zinn, C. E., et al. (2003). Harmonization of pulsed-field gel electrophoresis protocols for epidemiological typing of strains of methicillin-resistant Staphylococcus aureus: a single approach developed by consensus in 10 European laboratories and its application for tracing the spread of related strains. J. Clin. Microbiol. 41, 1574-1585. doi: 10.1128/JCM.41.4.1574-1585.2003

Müsken, M., Di Fiore, S., Römling, U., and Häussler, S. (2010). A 96-wellplate-based optical method for the quantitative and qualitative evaluation of Pseudomonas aeruginosa biofilm formation and its application to susceptibility testing. Nat. Protoc. 5, 1460-1469. doi: 10.1038/nprot.2010.110

Papadopoulos, P., Papadopoulos, T., Angelidis, A. S., Boukouvala, E., Zdragas, A., Papa, A., et al. (2018). Prevalence of Staphylococcus aureus and of methicillin-resistant S. aureus (MRSA) along the production chain of dairy products in north-western Greece. Food. Microbiol. 69, 43-50. doi: 10.1016/j.fm.2017.07.016
Pereyra, E. A., Picech, F., Renna, M. S., Baravalle, C., Andreotti, C. S., Russi, R., et al. (2016). Detection of Staphylococcus aureus adhesion and biofilm-producing genes and their expression during internalization in bovine mammary epithelial cells. Vet. Microbiol. 183, 69-77. doi: 10.1016/j.vetmic.2015.12.002

Price, L. B., Stegger, M., Hasman, H., Aziz, M., Larsen, J., Andersen, P. S., et al. (2012). Staphylococcus aureus CC398: host adaptation and emergence of methicillin resistance in livestock. MBio. 3:e00305-11. doi: 10.1128/mBio.00305-11

Rasmussen, G., Monecke, S., Ehricht, R., and Söderquist, B. (2013). Prevalence of clonal complexes and virulence genes among commensal and invasive Staphylococcus aureus isolates in Sweden. PLoS ONE 8:e77477. doi: 10.1371/journal.pone.0077477

Ribot, E. M., Fair, M. A., Gautom, R., Cameron, D. N., Hunter, S. B., Swaminathan, B., et al. (2006). Standardization of pulsed-field gel electrophoresis protocols for the subtyping of Escherichia coli O157:H7, Salmonella, and Shigella for PulseNet. Foodborne Pathog. Dis. 3, 59-67. doi: 10.1089/fpd. 2006.3.59

Rola, J. G., Czubkowska, A., Korpysa-Dzirba, W., and Osek, J. (2016). Occurrence of Staphylococcus aureus on farms with small scale production of raw milk cheeses in Poland. Toxins (Basel). 8:E62. doi: 10.3390/toxins80 30062

Rola, J. G., Korpysa-Dzirba, W., Czubkowska, A., and Osek, J. (2015). Prevalence of enterotoxin genes and antimicrobial resistance of coagulase-positive staphylococci recovered from raw cow milk. J. Dairy Sci. 98, 4273-4278. doi: 10.3168/jds.2014-9064

Rong, D., Wu, Q., Xu, M., Zhang, J. and Yu, S. (2017). Prevalence, virulence genes, antimicrobial susceptibility, and genetic diversity of Staphylococcus aureus from retail aquatic products in China. Front. Microbiol. 8:714. doi: $10.3389 /$ fmicb.2017.00714

Rosec, J. P., and Gigaud, O. (2002). Staphylococcal enterotoxin genes of classical and new types detected by PCR in France. Int. J. Food Microbiol. 77, 61-70. doi: 10.1016/S0168-1605(02)00044-2

Schlievert, P. M., Shands, K. N., Dan, B. B., Schmid, G. P., and Nishimura, R. D. (1981). Identification and characterization of an exotoxin from Staphylococcus aureus associated with toxic-shock syndrome. J. Infect. Dis. 143, 509-516. doi: $10.1093 /$ infdis/143.4.509

Schroeder, J. W. (2012). Bovine Mastitis and Milking Management. North Dakota State University. Available online at: http://www.clemson.edu/extension/ scaged/scffa/career-development-events/files/dairy-evaluation/mastitiscontrol-programs.pdf (Accessed 2018 March).

Shopsin, B., Mathema, B., Alcabes, P., Said-Salim, B., Lina, G., Matsuka, A., et al. (2003). Prevalence of agr specificity groups among Staphylococcus aureus strains colonizing children and their guardians. J. Clin. Microbiol. 41, 456-459. doi: 10.1128/JCM.41.1.456-45 9.2003

Silva, N. C., Guimarães, F. F., Manzi, M. P., Budri, P. E., Gómez-Sanz, E., Benito, D., et al. (2013). Molecular characterization and clonal diversity of methicillinsusceptible Staphylococcus aureus in milk of cows with mastitis in Brazil. J. Dairy Sci. 96, 6856-6862. doi: 10.3168/jds.2013-6719

Song, M., Bai, Y., Xu, J., Carter, M. Q., Shi, C., and Shi, X. (2015). Genetic diversity and virulence potential of Staphylococcus aureus isolates from raw and processed food commodities in Shanghai. Int. J. Food Microbiol. 195, 1-8. doi: 10.1016/j.ijfoodmicro.2014.11.020

Tarekgne, E. K., Skjerdal, T., Skeie, S., Rudi, K., Porcellato, D., Félix, B., et al. (2016). Enterotoxin gene profile and molecular characterization of Staphylococcus aureus isolates from bovine bulk milk and milk products of Tigray region, Northern Ethiopia. J. Food Prot. 79, 1387-1395. doi: 10.4315/0362-028X.JFP-16-003

Wang, D., Zhang, L., Zhou, X., He, Y., Yong, C., Shen, M., et al. (2016). Antimicrobial susceptibility, virulence genes, and randomly amplified polymorphic DNA analysis of Staphylococcus aureus recovered from bovine mastitis in Ningxia, China. J. Dairy Sci. 99, 9560-9569. doi: $10.3168 /$ jds. $2016-11625$

Wardyn, S. E., Forshey, B. M., and Smith, T. C. (2012). High prevalence of Panton-Valentine leukocidin among methicillin-sensitive Staphylococcus aureus colonization isolates in rural Iowa. Microb. Drug. Resist. 18, 427-433. doi: $10.1089 / \mathrm{mdr} .2011 .0239$ 
Xie, Y., He, Y., Gehring, A., Hu, Y., Li, Q., Tu, S. I., et al. (2011). Genotypes and toxin gene profiles of Staphylococcus aureus clinical isolates from China. PLoS ONE 6:e28276. doi: 10.1371/journal.pone. 0028276

Yan, Q., Wang, J., Gangiredla, J., Cao, Y., Martins, M., Gopinath, G. R., et al. (2015). Comparative genotypic and phenotypic analysis of Cronobacter species cultured from four powdered infant formula production facilities: indication of pathoadaptation along the food chain. Appl. Environ. Microbiol. 81, 4388-4402. doi: 10.1128/AEM.00359-15

Yan, X., Yu, X., Tao, X., Zhang, J., Zhang, B., Dong, R., et al. (2014). Staphylococcus aureus ST398 from slaughter pigs in northeast China. Int. J. Med. Microbiol. 304, 379-383. doi: 10.1016/j.ijmm.2013. 12.003

Zecconi, A., and Scali, F. (2013). Staphylococcus aureus virulence factors in evasion from innate immune defenses in human and animal diseases. Immunol. Lett. 150, 12-22. doi: 10.1016/j.imlet.2013.01.004
Zmantar, T., Chaieb, K., Makni, H., Miladi, H., Abdallah, F. B., Mahdouani, K., et al. (2008). Detection by PCR of adhesins genes and slime production in clinical Staphylococcus aureus. J. Basic. Microbiol. 48, 308-314. doi: 10.1002/jobm.200700289

Conflict of Interest Statement: The authors declare that the research was conducted in the absence of any commercial or financial relationships that could be construed as a potential conflict of interest.

Copyright (C) 2018 Wang, Lin, Jiang, Peng, Xu, Yi, Li, Fanning and Baloch. This is an open-access article distributed under the terms of the Creative Commons Attribution License (CC BY). The use, distribution or reproduction in other forums is permitted, provided the original author(s) and the copyright owner are credited and that the original publication in this journal is cited, in accordance with accepted academic practice. No use, distribution or reproduction is permitted which does not comply with these terms. 